Grace Liang

\title{
STRENGTHENING THE PSYCHIATRIC ADVANCE DIRECTIVE SYSTEM IN NEW ZEALAND: ALLOWING THE MENTALLY ILL TO HELP THEMSELVES
}

LLM RESEARCH PAPER

LAWS 513: Law and Medicine

FACULTY OF LAW

TE WHARE WĀNANGA O TE ŪPOKO O TE IKA A MĀU

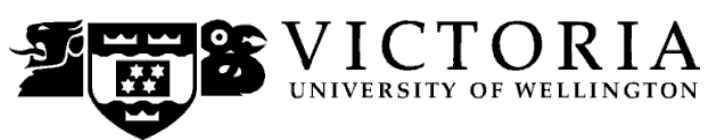

2013 


\section{Contents}

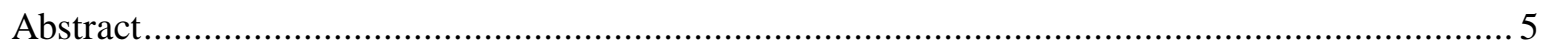

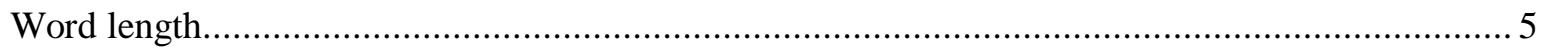

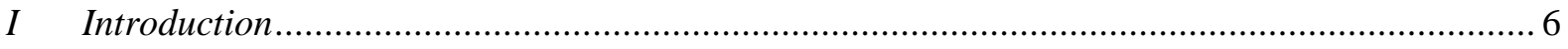

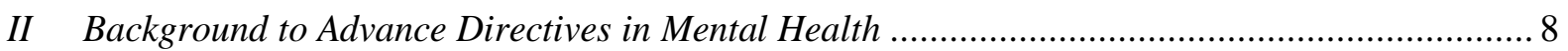

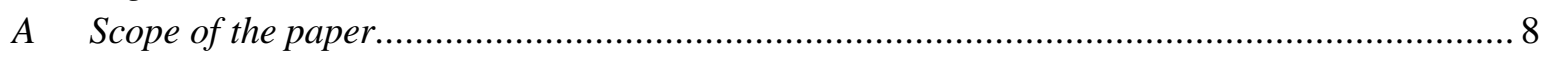

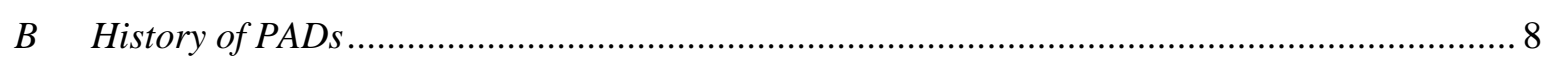

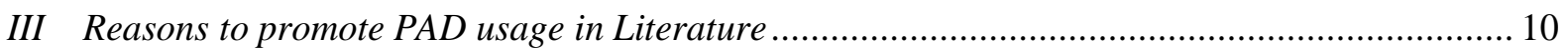

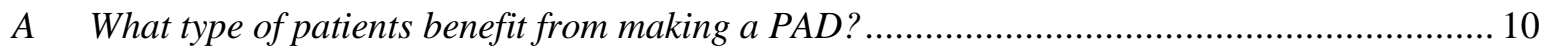

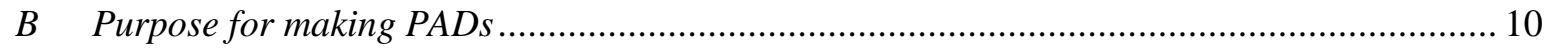

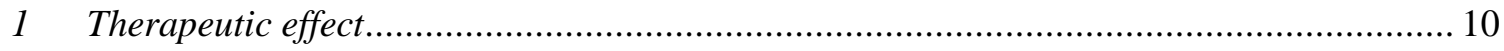

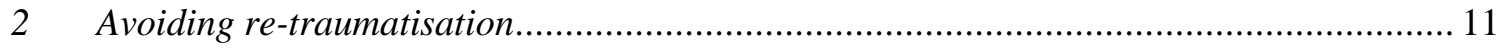

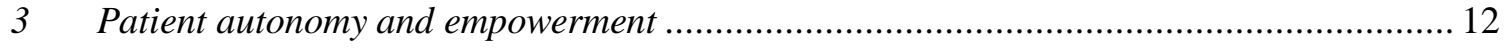

4 Avoiding the stigma of coercive treatment …................................................................ 12

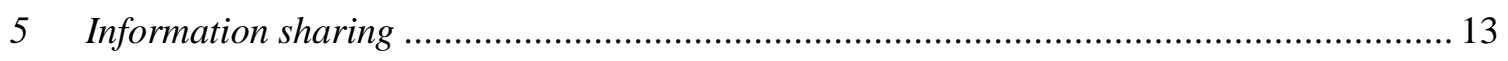

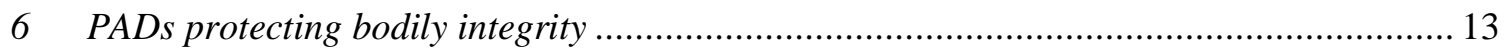

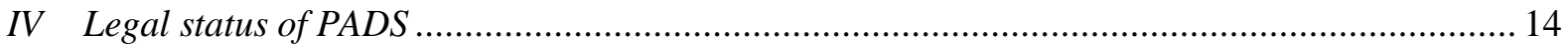

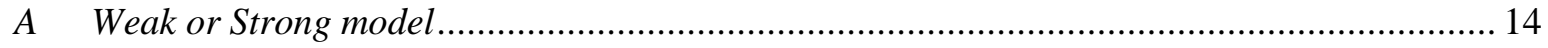

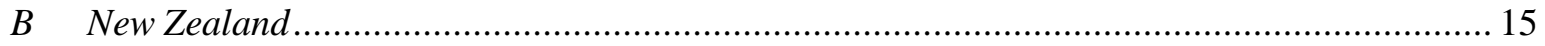

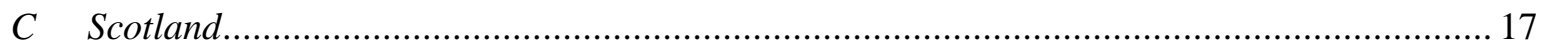

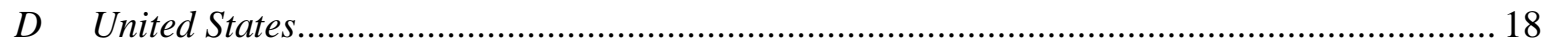

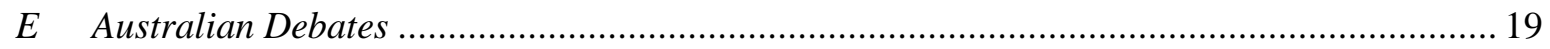

F United Nations Convention on the Rights of Persons with Disabilities ................................. 20

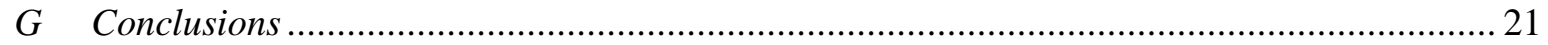

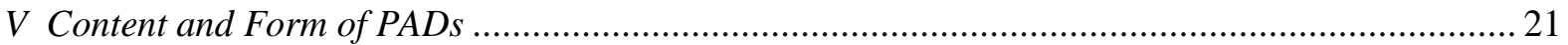

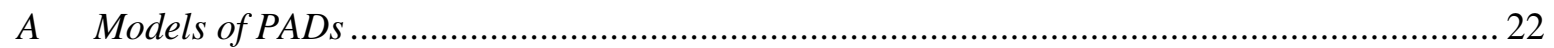

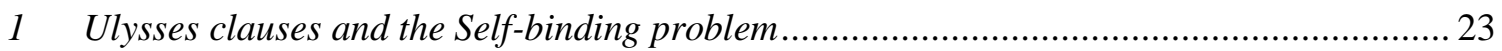

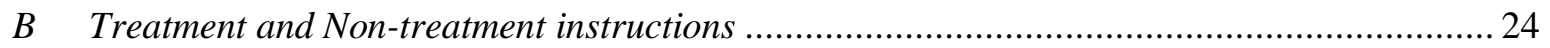

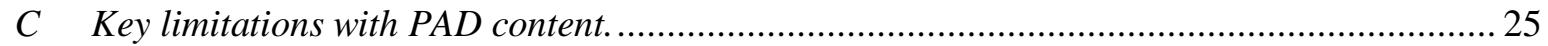

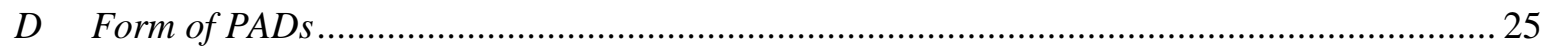

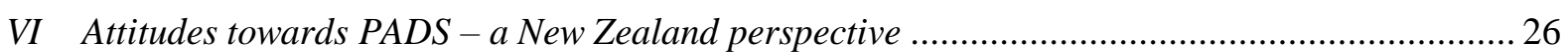

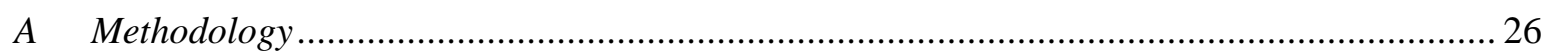




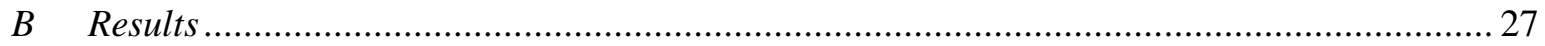

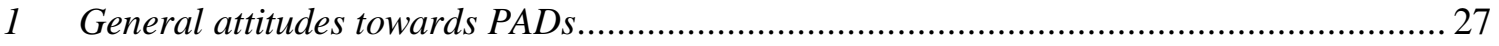

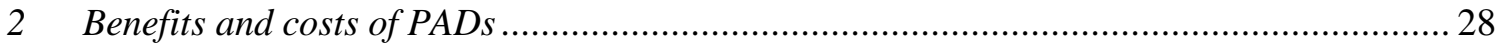

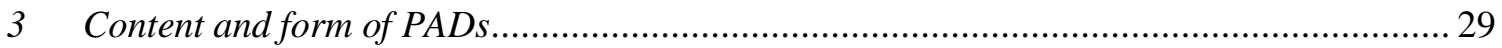

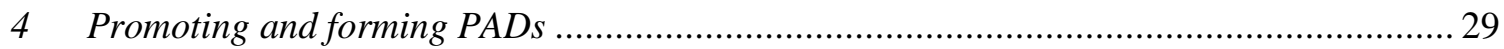

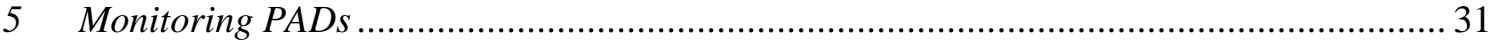

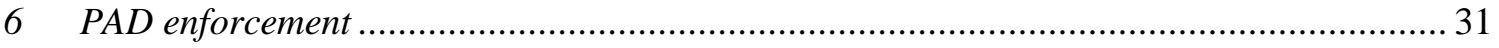

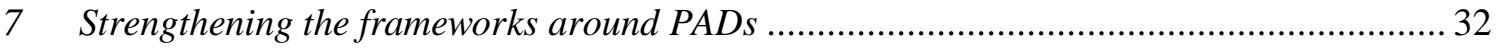

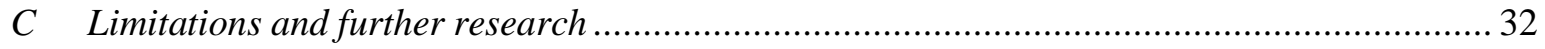

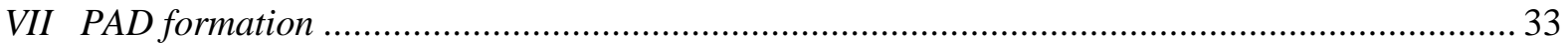

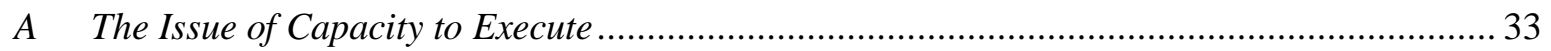

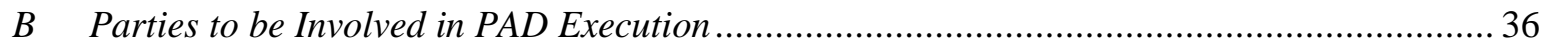

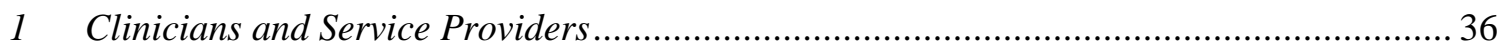

2 Consumer Advocates and Peer Support Networks ................................................ 37

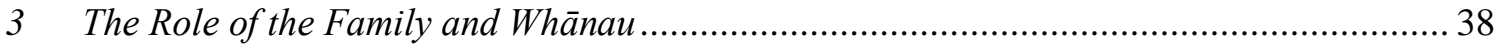

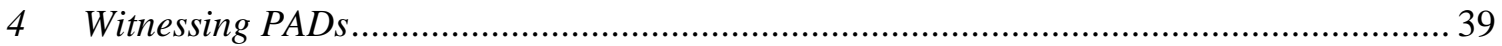

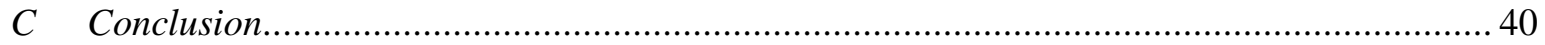

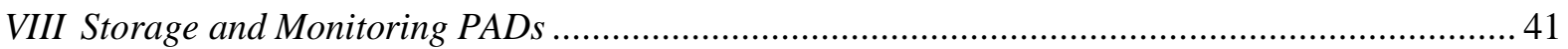

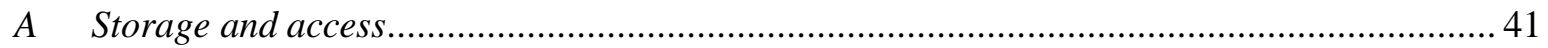

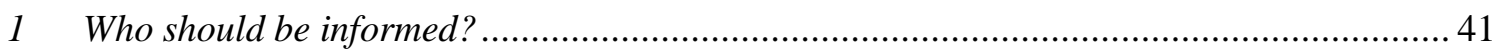

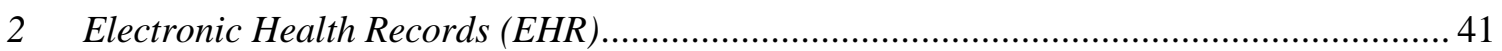

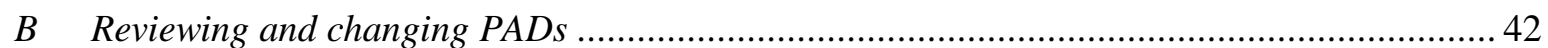

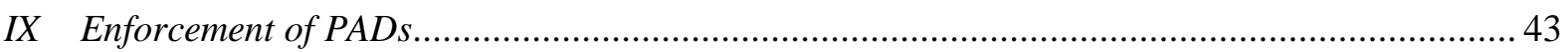

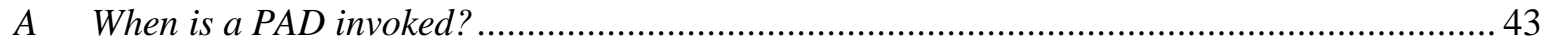

B Should the PAD be followed by the clinician? ....................................................... 45

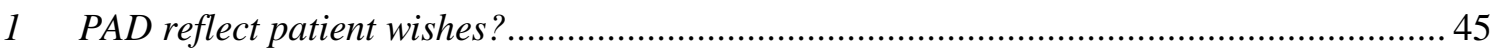

2 Patient current revocation of a valid PAD ........................................................ 46

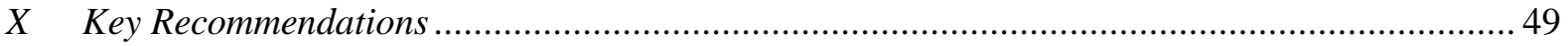

A Legislative Amendments .................................................................................. 49

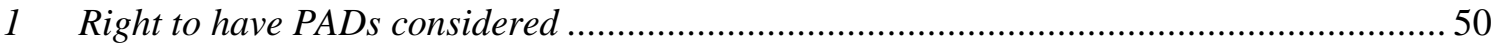

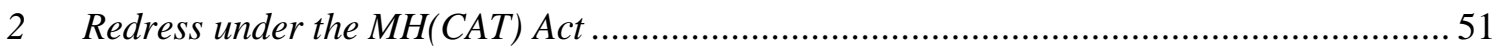

3 External PAD facilitator.......................................................................... 51

B Education and PAD Support Programme ................................................................ 51

$1 \quad$ Guidance for clinicians and legal professionals................................................. 51 


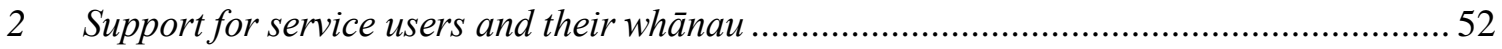

$3 \quad$ Support for advocates, NGOs, and peer support groups................................................. 52

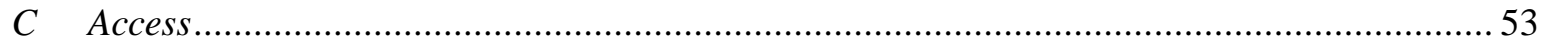

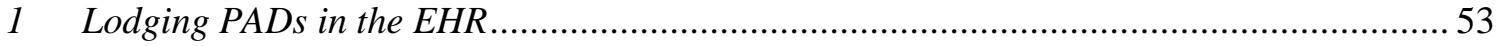

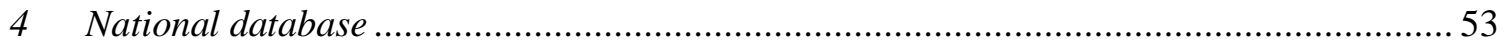

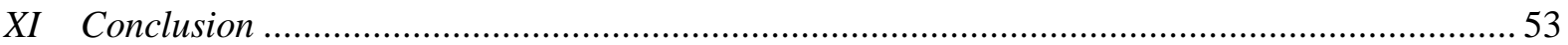

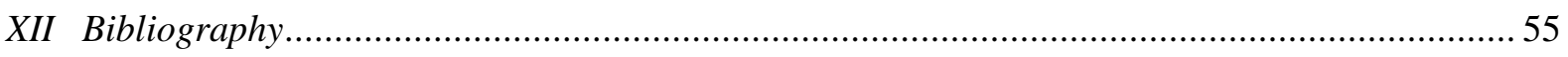

Appendix 1: Proposed parts to be added to the Mental Health (Compulsory Assessment and

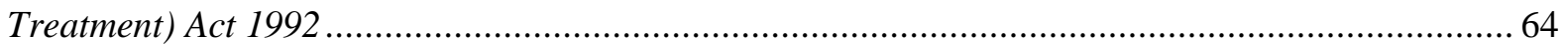

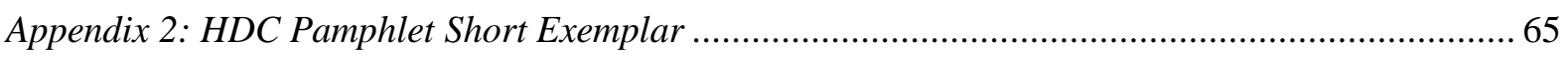

Appendix 3: New Zealand Medical Association General AD Form................................................ 66

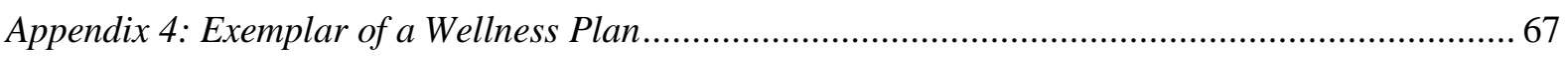

Appendix 5: Current differences between the PADs and Treatment/ Discharge/Wellness Recovery

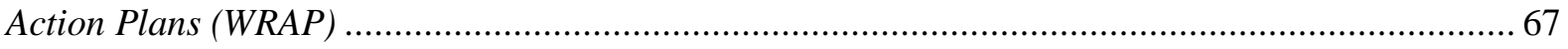

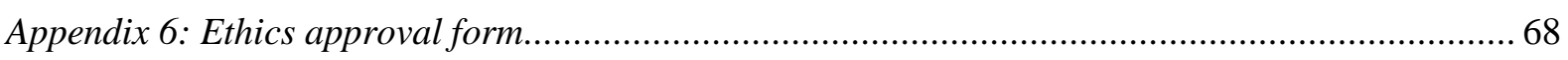

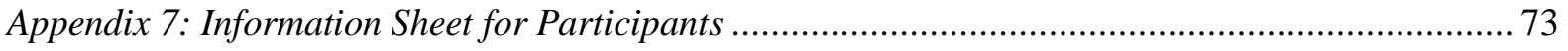

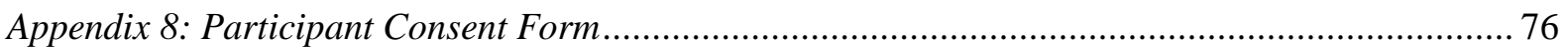

Appendix 9: Interview Questions on Psychiatric Advance Directives........................................... 77 


\begin{abstract}
Psychiatric advance directives (PADs) are an emerging method for adults with serious and persistent mental illness to manage their treatment by documenting treatment preferences in advance of periods of incapacity. However, the application of PADs has largely been neglected by the legal and psychiatric discourse in New Zealand. This paper presents some of the key purposes and unrealised benefits of PADs, and explains why New Zealand's law and policy surrounding advance directives in the mental health arena is unclear compared to other jurisdictions. Though interviews conducted with New Zealand clinicians and consumer advocates, key practical and legal dilemmas around forming, monitoring, and enforcing PADs were extracted and dissected. Interviews elucidated that, while attitudes were generally positive attitude towards PADs in the mental health system, the lack of a focused PAD strategy stifled its promulgation where it could most benefit service users. This paper proposes that PADs should be promoted, and articulates a normative PAD strategy for New Zealand.
\end{abstract}

\title{
Word length
}

The text of this paper (excluding abstract, table of contents, footnotes and bibliography) comprises approximately 15,078 words.

\section{Subjects and Topics}

Advance Directives in Mental Health

Mental Health (Compulsory Assessment and Treatment) Act 1992

Medical Best Practice 


\section{Introduction}

Psychiatric advance directives (PADs) are at the forefront of contemporary measures to reduce the involuntary treatment and detention of persons with mental illness. Embodying the slogan "nothing about us, without us", ${ }^{1}$ PADs are helpful strategies that give people with mental disorders more say in the management of their treatment. ${ }^{2}$ However, the application of advanced directives in the mental health arena is particularly contentious and has largely been neglected by legal and psychiatric discourse in New Zealand. ${ }^{3}$ To date, no information has been collected domestically on the number of people, although the estimated numbers are very low. ${ }^{4}$ This paper proposes that PADs should be promoted, and articulates a New Zealand-specific PAD strategy.

International jurisprudence has praised the use of PADs in modern psychiatry. Honouring the choices of individuals with disabilities when they are vulnerable and lack mental capacity has been labelled an international human rights issue that cannot be overlooked. ${ }^{5}$ PADs have been described as a solution which promotes patient autonomy, empowerment and selfdetermination. ${ }^{6}$ However, literature also details the technical and legal difficulties in making, monitoring and enforcing advance directives in practice. ${ }^{7}$ The lack of consumer understanding of the legal status of PADs and clinical scepticism over a document which is meant to limit treatment powers has resulted in a relatively small uptake and even smaller levels of clinical recommendation to patients.

New Zealand has a weak model of recognising PADs in law. Without a national PAD strategy, it can be assumed that the enforcement of PADs has been inconsistent, particularly due to varying patient circumstances, resource availability and differences in clinical opinion. Patients who would benefit from executing a PAD are not likely to see the value of creating

\footnotetext{
${ }^{1}$ Ross Phillips "Consumer Participation in Mental Health Research" (2006) 27 Social Policy Journal of New Zealand 171 at 171.

${ }^{2}$ Australian Capital Territory Department of Health Review of the ACT Mental Health (Treatment and Care) Act 1994 (Department of Health, Options Paper, November 2007) at 20.

${ }^{3}$ Pamela Wareham "New Zealanders making advance directives: A discourse analysis" (Masters in Health Science Thesis, Auckland University of Technology, 2005) at 22.

${ }^{4}$ Confidential interview with a psychiatrist, 4 September 2013.

${ }^{5}$ United Nation General Assembly Convention on the Rights of Persons with Disabilities: Resolution (adopted by the General Assembly 24 January 2007, A/RES/61/106) [UN Convention Rights]; World Health Organisation "WHO Resource Book on Mental Health, Human Rights and Legislation" (2005) WHO Library Cataloguing-in-Publication Data <www.who.int/mental_health/> at 17.

${ }^{6}$ Penelope Weller New Law and Ethics in Mental Health Advance Directives: the Convention on the Rights of Persons with Disabilities and the Right to Choose (Routledge, New York, 2013) at 10.

${ }^{7}$ Srebnik and Brodoff "Implementing Psychiatric Advance Directives: Service Provider Issues and Answers" (2003) 30(3) Journal of Behavioural Health Services and Research 253.
} 
them because it is perceived that they can simply be overridden by New Zealand's mental health legislation.

A good mental health service engages with relevant parties in collaborative discourse, so a focal point of this paper is the identification of the normative role of the parties surrounding the making, monitoring, and enforcement of PADs. What types of patients would benefit from making a PAD? Who should bear the burden of recommending and educating patients on PADs? And, who should attest to the validity of the PAD during enforcement? In answering these questions, this paper acknowledges the tension between providing a personalised health care service and the issue of finite resources and strains on health practitioners' time.

This paper firstly outlines the purpose of making a PAD in a mental health system that is increasingly becoming more open to patient choice, and less to clinical paternalism. This section introduces the different models of PADs, and how the content and form of the PAD will influence their enforceability in practice. Secondly, this paper analyses the precarious legal status of PADs in New Zealand law, and make comparisons to leading PAD jurisdictions including Scotland and the United States.

Part VI offers a window to the New Zealand attitudes towards PADs in mental health practice. Clinicians promoted the concept PADs but were wary of the increased strain on clinical practice, and burden on resources and time. Advocates had seen firsthand the usefulness of PADs for patient empowerment, and recommended their legal fortification. All participants agreed that PADs were underutilised, and its benefits under-recognised. From interviews conducted with a small group of leading mental health clinicians and advocates within the Wellington region, an interesting disparity in opinions was highlighted.

Based on the limited interviews, this paper explores both the legal and practical issues faced by stakeholders in the making, monitoring and enforcement of PADs. Many of the issues are backed by international literature, but how to address them is not clarified in our current advance directive framework. Finally this paper recommends a stronger and more transparent framework for PADs in New Zealand, where key actors are educated about their role in the system. 


\section{Background to Advance Directives in Mental Health}

$A$ Scope of the paper

This paper refers to advance directives in mental health as psychiatric advance directives (PADs). The paper focuses on treatment advance directives rather than personal statements about general life planning when a person loses capacity. The PADs discussed refer exclusively to written instructional directives rather than oral or proxy directives. This paper uses the terms 'patient', 'service-user', and 'consumer' interchangeably.

\section{B History of PADs}

Advance directive instruments, or living wills, resemble the traditional last will and testament. ${ }^{8}$ Advance directives were originally developed to allow persons to make decisions in relation to their end-of-life care, such as decisions to withdraw life support treatment ("do not resuscitate" orders), ${ }^{9}$ but they have subsequently been applied to mental health care. Generally, PADs enable individuals with mental illness to declare treatment preferences in the event of future mental incapacity. ${ }^{10}$ PADs generally only come into force after the person loses capacity or is incompetent to state their wishes.

Historically, the field of mental health has been governed by a desire among individuals with mental illness to break free from unwanted medical paternalism. ${ }^{11}$ Some perceive advance directives as legal instruments that allow patients to oppose a historical tradition of this paternalism. $^{12}$ Individuals with mental illness are keenly aware of the unequal bargaining power that can exist in making decisions with their physicians. Advance directives were seen as a pre-emptive tool to avoid unwanted medical treatment. ${ }^{13}$

\footnotetext{
${ }^{8}$ Tony Bogdanoski "Psychiatric advance directives: the new frontier in mental health law reform in Australia?" (2009) 16 JLM 891 at 892.

${ }^{9}$ RL O'Reilly “The Capacity to Execute an Advance Directive for Psychiatric Treatment” (2008) 31(1) Int'l JL \& Psychiatry 66 at 66.

${ }^{10}$ J Swanson and others "Superseding Psychiatric Advance Directives: Ethical and Legal Considerations" (2006) 34(3) Journal of the American Academy of Psychiatry and the Law 385 at 394.

${ }^{11}$ A B Rich "Medical Paternalism v Respect for Patient Autonomy: The More Things Change the More They Remain the Same" (2006) 10 Michigan State University College of Law Journal of Medicine and Law 87 at 89.

${ }^{12}$ D L Ambrosini "Psychiatric Advance Directives, Autonomy, and Choice: An Interdisciplinary Perspective from Law, Ethics, and Medicine" (Doctor of Philosophy Thesis, McGill University, 2011) at 55.

${ }^{13}$ Rosenson and Kasten "Another view of autonomy: arranging for consent in advance" (1991) 17

Schizophrenia Bulletin 1 at 1.
} 


\section{General Advance Directives vs PADs}

PADs can be distinguished from general advance directives in physical health care in three major aspects. First, people filling out general health care directives are often making decisions about end-of-life treatments they have never actually experienced. ${ }^{14}$ In contrast, psychiatric patients are generally dealing with chronic illness, and are therefore likely to have experienced the treatments they are describing. For example, a patient with schizophrenia, for example, may have opinions about which antipsychotic drug is most effective, and which ones have not worked in the past. ${ }^{15}$

Secondly, the goal of general advance directives is to increase the chance that life ends in comfort and dignity, whereas the goal of a psychiatric directive is often to maximise the chance of recovery while minimising unwanted interventions. ${ }^{16}$ More recent jurisprudence has recognised the power of PADs to give effect to patient participation and the human rights approach to recovery in mental health. ${ }^{17}$

Thirdly, the consequences of enforcing a general advance directive may also be different to enforcing PADs. Refusing treatment in end-of-life situations will usually hasten death. This can be seen as positive for the person (this is what they wanted) and arguably for their family, since not only have they respected the person's wishes but also do not have to watch a family member suffer. ${ }^{18}$ Refusing treatment for a mental illness is different to physical illness in that it is unlikely to lead to death. However, a possible result of following a refusal of treatment in a PAD is that the patient could become severely ill and remain ill in hospital for longer than if treated. ${ }^{19}$

\footnotetext{
${ }^{14}$ Bogdanoski, above n 8, at 892 .

${ }^{15}$ At 893 .

${ }^{16}$ Jacqueline M Atkinson Advance Directives in Mental Health (Jessica Kingsley Publishers, London, 2007) at 22; Harvard Health Publications "Making the most of psychiatric advance directives" (Mental Health Letter, 6 April 2006) at 1.

${ }^{17}$ P Weller "Psychiatric Advance Directives and Human Rights" 17(2) Journal of Psychology and Law 218 at 219.

${ }^{18}$ Atkinson, above n 16, at 23.

${ }^{19}$ At 24.
} 


\section{Reasons to promote PAD usage in Literature}

Approximately one in five New Zealanders suffer from some form of mental illness at some point in their lives. ${ }^{20}$ In 2009/2010, the District Health Board (DHB) saw 120,293 mental health clients. ${ }^{21}$ In a New Zealand health system which seeks to increase patient involvement and cooperation between clinician and patient and recognise the rights of the mentally ill, the use of PADs should be promoted. The following section elaborates on the justification for the increased use of PADs by service users in New Zealand

Unlike end-of-life situations that people may be able to imagine even from a young age, few people are likely to envisage developing a reoccurring mental illness and losing capacity. Therefore, the expectation is that a PAD will be made only by (or is only appropriate for) people who have experienced a major mental illness. ${ }^{22}$ This group of people are prone to having an acute episode in the future and therefore the most likely to find an advance directive useful. ${ }^{23}$ Information on which to base preferences specified in PADs will usually be derived from past treatment experiences as well as dialogue with treatment providers and others involved in a patient's life. ${ }^{24}$ Other groups that may take an interest in PADs include people who are at high risk of developing a major mental illness through genetic link, ${ }^{25}$ and those with poor language or other verbal communication abilities. ${ }^{26}$

\section{B Purpose for making PADs}

\section{Therapeutic effect}

A strong argument for protecting and increasing awareness of PADs is that they provide a mechanism to include the patient's "voice" during a mental health crises, when consumers are often least likely to have meaningful participation in treatment decisions. ${ }^{27}$ Nobody

\footnotetext{
${ }^{20}$ M Oakley Brown, J E Wells and K M Scott (eds) Te Rau Hinengaro: The New Zealand Mental Health Survey (Ministry of Health, September 2006) at 15.

${ }^{21}$ Ministry of Health Mental Health and Addiction: Service Use 2009/10 (February 2013) at 8.

${ }^{22}$ Papageorgiou and others "Advance directives for patients compulsorily admitted to hospital with serious mental illness" (2002) 181 British Journal of Psychiatry 513 at 513; Srebnik and others "The content and clinical utility of psychiatric advance directives" (2005) 56 Psychiatric services 592 at 598.

${ }^{23}$ Atkinson, above $\mathrm{n} 16$ at 133.

${ }^{24}$ Srebnik and Brodoff, above $\mathrm{n} 7$, at 257.

${ }^{25}$ Atkinson, above $\mathrm{n} 16$, at 23.

${ }^{26}$ Jacqueline M Atkinson Advance Directives in Mental Health (Jessica Kingsley Publishers, London, 2007) at 134.

${ }^{27}$ Srebnik and Brodoff, above n 7, at 254.
} 
understands an individual's needs and experiences as much as the individual themselves, and people react very differently to the same treatment. ${ }^{28}$ So unlike proxy directives, instructional PADs can accurately reflect the wants and needs of the patient, using the individual's own words. ${ }^{29}$

Through increased consumer participation, it has been argued that very execution of a PAD is therapeutic as it "provokes people who suspect that their problems might escalate to prepare treatment early, before the condition gets out of hand". ${ }^{30}$ Therefore, PADs can also support planned, effective crisis treatment by identifying and mobilising resources to de-escalate crises and serve as viable alternatives to hospitalisation. ${ }^{31}$

An often overlooked advantage of PADs is that the process of completing such documents allows individuals to gain insight, and learn how to self-manage their mental illness. For instance, individuals with depression are better able to deal with their illness when they are engaged as active participants rather than merely asked to comply with treatment. ${ }^{32}$

It has been accepted that coercive treatment does not work as well as treatment which is the subject of patient choice because of the therapeutic value deriving from a mutual dialogue and acceptance between patient and therapist. ${ }^{33}$ It follows that, in cases where a patient is capable of giving or refusing consent, it could be prudent to seek the patient's consent to foster the therapeutic relationship in spite of the statutory mandate to treat without consent.

In particular circumstances, a PAD may be created directly in response to a bad experience with treatment. The PAD could refer to refusals of treatment or care which are catalysts for a previous traumatic experience. If adhered to, the PAD can prevent re-traumatisation where an individual relives the same negative experiences from a previous treatment or life event. For example, a patient who has suffered from sexual abuse or rape may be reminded of this

\footnotetext{
${ }^{28}$ Confidential interview with a consumer advocate, 4 September 2013.

${ }^{29}$ Bogdanoski, above n 8 , at 893 .

${ }^{30}$ B Winick “Advance Directive Instruments For Those with Mental Illness” (1996) 51 U Miami L Rev 57 at 68.

${ }^{31}$ Srebnik and Brodoff, above n 7, at 254.

32 Dan Bilsker, Elliot M Goldner and Wayne Jones "Health Service Patterns Indicate Potential Benefit of Supported Self-Management of Depression in Primary Care" (2007) 52(2) Canadian Journal of Psychiatry 86 at 95.

${ }^{33}$ Sylvia Bell and Warren Brookbanks Mental Health Law in New Zealand $\left(^{\text {nd }}\right.$ ed, Brookers Ltd, Wellington, 2005) at [19.5].
} 
traumatic time if pinned down (or put in other forms of restraint) during compulsory treatment.

Without a PAD, and being unable to communicate, a common example of re-trauma can occur in the follow situation. During a recent hospitalisation, a patient struggles to explain to psychiatrists that certain anti-psychotic drug, especially Haldol, exacerbates their tardive dyskinesia - a neurological syndrome causing involuntary, rhythmic and often grotesque movements of the fact, lips and tongue. ${ }^{34}$ Dismissing the patient as incapable of speaking for themselves, the psychiatrist prescribed Haldol over the patient's protest. The unwanted treatment and associated loss of control left the patient opting for homelessness over the prospect of confinement. ${ }^{35}$

\section{$3 \quad$ Patient autonomy and empowerment}

Making an advance directive is about the exercise of autonomy - the autonomy of the competent person to decide their treatment in accordance with the principle of informed consent. $^{36}$ This may be exercised in different ways. Opting out of the treatment may be motivated by the desire of the well person to preserve more of the autonomy by avoiding the side-effects of some treatments. ${ }^{37}$ Equally, the motivation to opt out may have to do with preserving the 'autonomy' of the person when ill, or indeed, the existence of the ill person. ${ }^{38}$

However, opting into treatment may have more to do with preserving the autonomy of the well person. For most people this would be assumed to be the rational choice. Often they are also choosing the timing of the treatment as well as the type of treatment. Although the autonomy of the competent person may be limiting the capacity of the future incompetent person, this is generally accepted given the competent person is giving informed consent.

\section{$4 \quad$ Avoiding the stigma of coercive treatment}

PADs can avoid the stigma of the formal scheduling process and provide an alternative to legal coercion. Formal civil commitment proceedings, or the "scheduling" of involuntary patients, could be limited if patients included provisions in a PAD instrument to the effect

\footnotetext{
${ }^{34} 18$ Former State Mental Health Commissioners, the National Mental Health Association, and Others 'Brief of 18 Former State Mental Health Commissioners, The National Mental Health Association, and others as Amici Curiae in support of the Appellees', Submission in Hargrave v Vermont 02-7160, 3 July 2002, at 12.

${ }^{35}$ At 12.

${ }^{36}$ B Winick "The Right to Refuse Mental Health Treatment: A Therapeutic Jurisprudence Analysis" (1994) 17 Int'l JL \& Psychiatry 99 at $100-111$.

${ }^{37}$ Bogdanoski, above n 8, at 899 .

${ }^{38}$ Atkinson, above 16, at 82.
} 
that certain treatment or hospitalisation be provided to them on a voluntary basis notwithstanding an incompetent refusal by the patient. ${ }^{39}$ Such "voluntary commitment contracts" would benefit those patients in particular who have previously had positive hospital experiences, but found the scheduling process to be demeaning, and can foresee future periods of civil commitment due to the relapsing nature of their mental illness. ${ }^{40}$

\section{$5 \quad$ Information sharing}

For clinicians and practitioners, PADs can serve as a repository for patient histories on treatment preferences. ${ }^{41}$ In particular, for clinicians treating a patient with whom they have had no previous history, a PAD provides insightful information on treatments that have proven effective on the patient. A PAD that specifies treatment that has previously been successful or very unsuccessful may help a clinician not make the same mistake again. On a wider scale, there may also be improved communication between users, family members and providers in the sense that a consensus about appropriate forms of treatment can be met and set in place before crisis. ${ }^{42}$ The New Zealand Medical Association recognises the advantages of advance statements in terms of encouraging openness, dialogue and forward planning between all parties involved in making and enforcing PADs. ${ }^{43}$

\section{$6 \quad$ PADs protecting bodily integrity}

PAD gives people who suffer from mental illness - and who are more likely to be subjective to coercive treatment $-\mathrm{a}$ voice to reject medication that puts their general health at risk. ${ }^{44}$ Even when administered correctly, psychotropic drugs have been known to have particularly severe side effects, and in extreme cases could cause fatality. ${ }^{45}$ They are described to "intervene in the deepest functions of personhood" and "are mind altering". 46 Although the new atypical anti-psychotic drugs are deemed safer, it has still been known to cause weightgain, sexual dysfunction, and significantly increase the chance of developing diabetes

\footnotetext{
${ }^{39}$ Winick, above n 30, at 68 .

${ }^{40}$ A Buchanan and D Brock Deciding for Others: The Ethics of Surrogate Decision Making (Cambridge University Press, London 1990) at 351.

${ }^{41} 18$ Former State Mental Health Commissioners, the National Mental Health Association, and Others, above n 34 , at 6.

42 At 8.

${ }^{43}$ New Zealand Medical Association “Advance Directives” (2007) New Zealand Medical Association website $</ /$ www.nzma.org.nz/>.

${ }^{44}$ Robert Bernstein "Commentary: The Climate for Physician Adherence to Psychiatric Advance Directives" (2006) 34(3) The Journal of American Academy of Psychiatry and the Law 402 at 402.

45 J Dunlap "Psychiatric Advance Directives: Having One's Say?" (2001) 89 Kentucky Law Journal 327 at 368.

${ }^{46}$ Steinkruger v Miller (2000) 612 NW 2d 591 at 597 at [15].
} 
mellitus. PADs give people a platform to expressly refuse these treatments on grounds of bodily integrity. ${ }^{47}$

\section{Legal status of PADS}

General advance directives are given legal status by the common law, although many jurisdictions have specifically enacted PAD legislation to fortify their status. It is common amongst most legal jurisdictions that an advance directive is 'trumped' by the use of a Mental Health Act which allows for compulsory treatment, even if the person objects and has so stated in an advance directive. ${ }^{48}$ This section compares the New Zealand legal status of PADs to two leading jurisdictions, Scotland and United States, as well as a developing jurisdiction, Australia. It is argued that New Zealand's weak status for PADs is a major contributing factor to their underutilisation.

\section{A Weak or Strong model}

This dimension concerns how binding the advance directive is on treating clinicians (and possibly others) - in other words their status in law. ${ }^{49}$ In Commonwealth jurisdictions the legislatures have tended to place mental health advance directives in weak legal frameworks. ${ }^{50}$

In New Zealand, the Code of Health and Disability Services Consumers' Rights 1996 (The Code) creates a weak model of protection of PADs, making them subordinate to mental health laws. This approach reflects an assumption that weak recognition of mental health advance directives will encourage the development of good clinical practices. ${ }^{51}$ However, this is not true in New Zealand's case. The weak model is typically justified on the basis that the purpose of such laws is to clarify the common law, promote rights, and rebut the prevailing assumption that the principles of advance care planning do not apply in mental health settings.

\footnotetext{
4718 Former State Mental Health Commissioners, the National Mental Health Association, and Others, above n 34 , at 19.

${ }^{48}$ Phil Barker (ed) Mental Health Ethics: the Human Context (Routledge, New York, 2011) at 749.

49 Atkinson, above n 16, at 47.

${ }^{50}$ Weller, above n 6, at 160.

${ }^{51}$ At 160 .
} 


\section{B New Zealand}

New Zealand takes a minimalist approach to recognising PADs. Right 7(5) of the Code allows consumers to use an advance directive in accordance with the common law. ${ }^{52}$ The phrase "advance directive" is defined in cl 4 to mean:

A written or oral directive -

(a) by which a consumer makes a choice about a possible future health care procedure; and

(b) that is intended to be effective only when he or she is not competent.

Right 7(7) provides that "every consumer has the right to refuse services and to withdraw consent to services". ${ }^{53}$ Both of these rights are derived from s 11 of the New Zealand Bill of Rights Act 1990, which provides for the right to refuse to undergo treatment, and is underpinned by the principle of autonomy. ${ }^{54}$ While other jurisdictions have specific legislation setting out requirements to be met before an advance directive is legally valid, ${ }^{55}$ there is no equivalent legislative clarification in New Zealand. Moreover, the validity of advance directives at common law is unclear in New Zealand. ${ }^{56}$ What is clear is that a PAD will not override the ability of a clinician to authorise compulsory treatment if the patient is subject to a compulsory treatment order under the Mental Health (Compulsory Assessment and Treatment) Act $1992 .{ }^{57}$

The Guidelines to the Mental Health (Compulsory Assessment and Treatment) Act 1992 (MH(CAT) Act), issued by the Ministry of Health in April 2000, sought to reinforce clinical recognition of the PAD directive by noting that the concept of "best interests" encompasses the requirement that a PAD must be considered in the determination of best interests. ${ }^{58}$ To mitigate legal uncertainty, it is suggested that preparation of an advance directive be made

\footnotetext{
${ }^{52}$ Health and Disability Commissioner (Code of Health and Disability Services Consumers' Rights) Regulations 1996. [Code of Rights].

${ }^{53}$ Also see R Stent A Review of the Health and Disability Commissioner Act 1994 and Code of Rights for Consumers of Health and Disability Services: Review Document for Consultation. (Health and Disability Commissioner, Consultation Document, 1999) at 41.

${ }^{54}$ Pauline Wareham, Antoinette McCallin and Kate Diesfeld "Advance Directives: The New Zealand Context" (2005) 12(4) Nursing Ethics 349 at 351.

${ }^{55}$ S Johnson (ed) Health Care and the Law ( $3^{\text {rd }}$ ed, Brookers Ltd, Wellington, 2004) at 102.

${ }^{56}$ At 102.

${ }^{57}$ Mental Health (Compulsory Assessment and Treatment) Act 1992, s 59.

${ }^{58}$ Karen O Poutasi Guidelines for Medical Practitioners Using Sections 110 and 110A of the Mental Health (Compulsory Assessment and Treatment) Act 1992 (Ministry of Health, Guidance Paper, April 2000).
} 
with the involvement of family, a GP, and even a lawyer. ${ }^{59}$ In the New Zealand context, legal advice is helpful if the practitioner believes that there is strong family opposition to the contents of the $\mathrm{AD}$ and states "a valid $\mathrm{AD}$ must be made, without undue influence, by a competent person, who is fully informed about refusing the service in the future" ${ }^{60}$

An advance directive of any kind will be held to be valid if the following four considerations are met: ${ }^{61}$

1) the consumer was competent to make decisions (when PAD was made);

2) the consumer made decision free of undue influence;

3) the consumer was sufficiently informed to make the decision; and

4) the consumer intended the directive or choice to apply to the present circumstances.

Alternatively, or in conjunction with a PAD, a patient may also establish an enduring power of attorney (EPA) under s 98 of the Protection of Personal and Property Rights Act 1988. The patient grants the attorney the power to make decisions on becoming incompetent and unable to make decisions. ${ }^{62}$. However, the proxy cannot refuse consent to standard medical treatment to save the person's life. ${ }^{63}$

It is at least arguable that, while New Zealand legislation does not specifically endorse advance directives, it nevertheless contemplates patients playing a role in deciding to some extent the nature of their treatment. ${ }^{64}$ Part 5 of the MH(CAT) Act presumes that a patient is competent to refuse treatment. This is reflected in provisions such as s 58(4), which directs the responsible clinician to attempt to obtain the consent of the patient to any treatment even thought that treatment may be authorised by or under [the] Act without the patient's consent.

The presumption that a patient will be involved in deciding the nature of their treatment is also reflected in a number of the rights included in MH(CAT) Act in Part 6 (Rights of patients, particularly s 64 (General rights to information), s 66 (Rights to treatment), and s 67 (Right to be informed about treatment). But this presupposes that an individual has the

\footnotetext{
${ }^{59}$ Health and Disability Commissioner "Advance Directives in Mental Health Care and Treatment: Information for mental health service users" Mental Health Commission <www.hdc.org.nz>.

${ }^{60}$ Johnson, above n 55, at 102.

${ }^{61}$ Health and Disability Commissioner "Advance Directives, Living Wills and Questions of Competence: Presentation to the New Zealand Hospitals Association Conference 'Chance or Choice - Staying Motivated in Aged Care" (1997) Health and Disability Website <www.hdc.org.nz/>.

${ }^{62}$ Skegg and Paterson (eds) Medical Law in New Zealand (Thomson Brookers, Wellington, 2006) at [6.2.2].

${ }^{63}$ A Bray and J Dawson Who benefits from welfare guardianship? A study of New Zealand law and people with intellectual disabilities (Donald Beasley Institute, Dunedin, 2000) at 55.

${ }^{64}$ Bell and Brookbanks, above n 33, at [19.5].
} 
capacity to communicate their opinions and comprehend information about treatment at crisis point.

C Scotland

In comparison to New Zealand, Scotland's comprehensive legislative coverage of PADs puts them at the other end of the legal spectrum. The ground-breaking Mental Health (Care and Treatment)(Scotland) Act 2003 was enacted in reaction to the Millan Committee report, ${ }^{65}$ which highlighted concern about the way people with disabilities were being treated under compulsory treatment orders. ${ }^{66}$ This Act gives patients the right to make and withdraw written statements that include information about how they would wish to be treated and how they would not wish to be treated, if they lose capacity to decide on treatment. ${ }^{67}$

The Act requires the Mental Health Tribunal, persons authorised to give medical treatment under the Act, and designated medical practitioners ${ }^{68}$ to have regard to the wishes expressed in ADs. ${ }^{69}$ If such persons, tribunals or treating medical practitioner make a decision that conflicts with the PAD, they are required to provide a statement in writing that sets out the reasons why a conflicting decision has been made. ${ }^{70}$ The decision must be communicated to guardians and advocates, a copy placed on the patient's medical record, and reported to the Mental Welfare Commission for Scotland. ${ }^{71}$

Other processes intended to enhance the ability of people with mental illness to participate fully include: $:^{72}$

- consider the view of patient's "named" person, carers, guardians, and welfare attorneys; ${ }^{73}$

- the importance of patient participation as fully as possible in all decisions; ${ }^{74}$

\footnotetext{
${ }^{65}$ Rt Hon Bruce Millan New Directions: Report on the Review of the Mental Health (Scotland) Act 1984 (SE/ 2001/ 56) [The Millan Report].

${ }^{66} \mathrm{P}$ Weller "Advance directives and the translation of human rights principles in mental health law - towards a contextual analysis" (paper presented at the Quarterly Mental Health Consumer, Carer and Community Forum, ACT, May 2008) at 2.

${ }^{67}$ Mental Health (Care and Treatment) (Scotland) Act 2003, s 275.

${ }^{68}$ Section 276

${ }^{69}$ Section 276(3).

${ }^{70}$ Section 276(7).

${ }^{71}$ Section 276(8).

72 Part 1.

${ }^{73}$ Section $1(3)(b)(i)$.

${ }^{74}$ Section 1(3)(c).
} 
- the importance of providing such information and support to the patient as is necessary to enable the patient to participate $;^{75}$

- the importance of providing the maximum benefit to the patient, ${ }^{76}$

- the need to ensure that, unless it can be shown that it is justified in the circumstances, the patient is not treated in a way that is less favourable than the way in which a person who is not a patient might be treated in a comparable situation; ${ }^{77}$ and

Considered in full, the Scottish mental health scheme seeks to address the communicative barriers that limit the opportunity of people living with mental illness to receive appropriate mental health care. ${ }^{78}$ In doing so, the scheme maximises the participation of persons in the medical decisions that affect them. ${ }^{79}$

\section{D $\quad$ United States}

Long before Scotland passed their PAD legislation, the United States pioneered the concept of an Advance Directive strategy. The introduction of the federal Patient Self Determination Act 1991 (PSDA), subsequently passed by over 25 states, led to widespread recognition of PADs in state legislation. ${ }^{80}$ The Act requires that patients admitted to federally funded hospitals be informed about their right under state law to prepare an advance directive. The hospital is obliged to inquire and document whether the patient has executed an $\mathrm{AD}$, to respect the documentation, and to educate health care providers regarding its use. ${ }^{81}$ Common to all of these statutes are limitations that allow for PADs to be overridden by mental health professionals without incurring civil liability, where failing to comply with the PAD breaches a duty of care owed by mental health professionals to the patient or to the third parties. ${ }^{82}$ Further, these statutes do not allow patients to use PADs to avoid emergency involuntary detention. ${ }^{83}$

The United States Living Wills Registry provides a good example of a national initiative which "electronically stores advance directives, and makes them available to health care

\footnotetext{
${ }^{75}$ Section 1(3)(d).

${ }^{76}$ Section 1(3)(f).

${ }^{77}$ Section $1(3)(\mathrm{g})$.

${ }^{78}$ Atkinson, above n 16, at 159

${ }^{79}$ At 222.

${ }^{80}$ Ambrosini, above $\mathrm{n}$ 12, at 159.

${ }^{81}$ Weller, above $\mathrm{n} 17$, at 220.

82 Bogdanoski, above n 8, at 894.

${ }^{83}$ M S DeWolf Bosek, M E Ring and R Cady, "Do Psychiatric Advance Directives Protect Autonomy?" (2008) 10(1) JONA's Healthcare Law, Ethics and Regulation 17 at 21.
} 
providers 24 hours per day via secure Internet or telephone-facsimile". ${ }^{44}$ This registry has significantly improved the accessibility of PADs by mental health care providers during crises or emergencies where patients do not carry a card on them.

Moreover, the National Resource Centre on Psychiatric Advance Directives is an online database that provides detailed information about the state laws. ${ }^{85}$ This comprehensive database, which is spearheaded by leading United States PAD experts and academics, ${ }^{86}$ aims to educate citizens about the law in their state and empower individuals and their support networks to charge of their own health planning.

\section{E $\quad$ Australian Debates}

Over the last 5 years, the Australian psychiatric community has pushed for recognition of PADs in Australian law. ${ }^{87}$ The Australian Human Rights Commission investigated the issue of living wills as applied to human rights of persons with mental disabilities almost 10 years ago, citing that PADs in mental health "participation and consultation are cornerstones of the National Mental Health Strategy" ${ }^{88}$ However, very little action has been taken, despite HRC recommended that "psychiatric living wills [to be] formally recognised and registered by a Guardian Board or Mental Health Review Tribunal". ${ }^{89}$

The Australian Capital Territory has been the only Australian jurisdiction to give serious consideration to legislating for PADs by giving competent persons the right to consent to or refuse future medical treatment through "health directives" and/or appointed health care proxies. A review of the Mental Treatment (Treatment and Care) Act 1994 (ACT) ${ }^{90}$ has specifically considered whether the legal recognition of PADs is necessary as part of its overall human rights-based reform of the Act. ${ }^{91}$ The major suggestion is that recognition and

\footnotetext{
${ }^{84}$ Bogdanoski, above n 8 , at 897.

${ }^{85}$ See National Resource Centre on Psychiatric Advance Directives Website <www.nrc-pad.org/>.

${ }^{86}$ National Resources Center on Psychiatric Advance Directives "Who We Are" (2013) NRC PAD <www.nrcpad.org/>.

${ }^{87}$ See National Advance Care Directives Working Group A National Framework for Advance Care Directives (Australian Health Ministers' Advisory Council, Consultation Document, 2011).

${ }^{88}$ Human Rights and Equal Opportunity Commission "Discussion Paper: Living Wills" (1999) The Australian

Human Rights Commission <www.humanrights.gov.au/publications/discussion-paper-living-wills>; Bogdanoski, above n 8 .

${ }^{89}$ Human Rights and Equal Opportunity Commission, above n 88.

${ }^{90}$ Medical Treatment (Health Directive) Act 2006 (ACT).

${ }^{91}$ Australian Capital Territorial Department of Health, above n 2, at 22.
} 
guidance to $\mathrm{ADs}$ and PADs be brought under one unifying Act. The legislative discourse continues in mental health circles today. ${ }^{92}$

\section{F $\quad$ United Nations Convention on the Rights of Persons with Disabilities}

New Zealand ratified ${ }^{93}$ the United Nations' Convention on the Rights of Persons with Disabilities $^{94}$ in 2008 (CRPD). The CRPD clarifies the obligations on State Parties to promote and ensure the rights of persons with disabilities and sets out the steps that should be taken to ensure equality of treatment. ${ }^{95}$ It goes into much more detail than previous general human rights conventions and the non-legally binding Principles for the Protection of Persons with Mental Illness and the Improvement of Health Care, ${ }^{96}$ concerning what action needs to be taken to prohibit discrimination.

The CRPD is clear that State Parties must recognise that persons with disabilities enjoy legal capacity on an equal basis with others in aspects of life. ${ }^{97}$ This means looking at the decision making supports people might need to be able to exercise this right. ${ }^{98}$ Mental health advance directives can be seen as one of the avenues of supporting optimal decision making. ${ }^{99}$ The promulgation of the CRPD calls for a closer engagement with disability rights as they are expressed in international human rights law. ${ }^{100}$

The CRPD provides a framework that encourages a new approach to mental health advance directives. As a tool for the realisation of positive entitlements in mental health care, there are three key observations that flow from the human rights analysis of PADs. These are that the CRPD privileges the perspectives of people with mental health conditions in all

\footnotetext{
92 "The MHS 2013 S93: Advance Directives Feature Symposium: Consumers of Mental Health Services making Advance Statements: the challenges and opportunities" (23 August 2013) Mental Health Connect Blog of The MHS Conference <mentalhealthconnect.com.au>.

${ }^{93}$ Disability (United Nations Convention on the Rights of Persons with Disabilities) Act 2008.

${ }^{94}$ United National Convention on the Rights of Persons with Disabilities 2515 UNTS 3 (opened for signature 30 March 2007, entered into force 3 May 2008).

${ }^{95}$ Weller, above $\mathrm{n} 6$, at 2.

${ }^{96}$ United Nations Principles for the Protection of Persons with Mental Illness and the Improvement of Mental Health Care GA Res 46/119, A/Res/46/119 (1991), principle 11.

${ }^{97}$ Weller, above $\mathrm{n} 6$, at 13 .

${ }^{98}$ At 13.

${ }^{99}$ At 67.

${ }^{100}$ At 13 .
} 
matters $;{ }^{101}$ encourages approaches to the adjudication of human rights that adopt principles of proportionality; ${ }^{102}$ and supports the use of mental health advance directives as a human rights tool. ${ }^{103}$ A fuller discussion of how PADs can help New Zealand achieve compliance with the CRPD is beyond the scope of this paper, but there has been increasing interest in this area of analysis in international literature. ${ }^{104}$

\section{G Conclusions}

When compared to international jurisdictions, the New Zealand 'law' and policy on the formation, monitoring and enforcement of PADs is very weak and leaves much discretion to clinician and patients. Despite the call within the New Zealand medical profession to have clear, and nationally consistent guidance for PADs, ${ }^{105}$ this has not yet to be achieved.

\section{$V$ Content and Form of PADs}

Where advance directives in mental health have been introduced, concerns have been expressed by clinicians and others about the content of advance statements, including inappropriate treatment choices, ambiguity, or the impact of such decisions on resources. ${ }^{106}$ A frequently expressed concern is that patients will refuse all treatment in a PAD, and the impact this will have on resources. ${ }^{107}$ However, research in both the United States and England suggests that it is very uncommon for people to refuse all medication. ${ }^{108}$

\footnotetext{
${ }^{101}$ Weller, above n 6, at 161.

${ }^{102}$ At 135 .

103 At 161

${ }^{104}$ See Weller, above n 6; Weller, above n 66.

105 New Zealand Medical Association, above n 43, at [12].

106 See P Backlar "Anticipatory planning for end-of-life care is not quite like anticipatory planning for psychiatric treatment” (1997) 33 Community Mental Health Journal 261; R Dresser "Advance Directives: Implications for Policy" (2004) 24 Hastings Centre Report S2; D E Hoffman, S I Zimmerman and C J Tompkins "The dangers of directives or the false security of forms" (1996) 24 Journal of Law and Medical Ethics 5.

${ }^{107}$ P Appelbaum "Psychiatric Advance Directives and Treatment of Committed Patients" (2004) 55 Psychiatric Services 751; Elbogen and others "Clinical decision-making and views about psychiatric advance directives" 57 Psychiatric Services 350; Halpern and Szmukler "Psychiatric advance directives: Recognising autonomy and non-consensual treatment" (1997) 21 Psychiatric Bulletin 8; Papageorgiou and others, above n 22.

${ }^{108}$ P Backlar and others "Consumer, Provider, and Informal Caregiver Opinions on Psychiatric Advance Directives (2001) 28 Administration and Policy in Mental Health 609; P S Sherman "Computer-assisted creation of psychiatric advance directives" (1998) 34 Community Mental Health Journal 351; Srebnik and others "The content and clinical utility of psychiatric advance directives" (2005) 56 Psychiatric services 592.
} 
A number of factors might influence the content of a treatment PAD. The law differs in different jurisdictions as to what content PADs should specify. ${ }^{109}$ The content and form of PADs can trigger legal issues which question the validity, revocability, and enforceability of these documents. The limited New Zealand guidelines on content are ill-equipped to help clinicians, patients and support people to address these issues. This section will first discuss the different models of PADs, then make suggestions about the type of content which create problems in practice. It is concluded that what treatments people choose to write down is largely individualistic, and therefore can vary greatly.

$A$

\section{Models of PADs}

PADs allow the person either to refuse treatment (proscriptive) or agree to treatment (prescriptive) or a mixture of both. In the latter case, for example, a person may refuse some medication but agree to take another. For example, they may refuse depot injections but agree to oral medications. ${ }^{110}$

One question is whether advance acceptance of treatment is the same type of consent as advance refusal of treatment, or whether the two types of decision are qualitatively different. It is recognised that, while there is a right to refuse treatment, ${ }^{111}$ and an entitlement to medical treatment where appropriate, ${ }^{112}$ there is no entitlement to demand specific treatment. Part of the concern will have to do with the relationship of the advance, competent decision with the current, incompetent decision.

But as compulsory, or mandated, treatment in the community becomes a more common option ${ }^{113}$ the possibility of using an opt-in advance directive to avoid compulsory treatment may increase. Patients may be persuaded that being treated under an opt-in advance directive (and thus being voluntarily treated) is 'better' (less stigmatising) than being treated involuntarily. ${ }^{114}$

\footnotetext{
${ }^{109}$ Reilly and Atkinson "The content of mental health advance directives: Advance statements in Scotland" (2010) 33 International Journal of Law and Psychiatry 116.

${ }_{110}$ Atkinson, above n 16, at 49.

${ }^{111}$ Code of Rights, above n 52, Right 7(7).

${ }^{112}$ Mental Health (Compulsory Assessment and Treatment) Act 1992, s 66.

${ }^{113}$ Monahan and others "Mandated Community Treatment" (2001) 52 Psychiatric Services 1192.

${ }^{114}$ Scottish Executive Mental Health (Care and Treatment) (Scotland) Act 2003 Code of Practice (Vol 1) (August 2005) at [59].
} 


\section{$1 \quad$ Ulysses clauses and the Self-binding problem}

Ulysses clauses are a type of opt-in treatment usually discussed in the context of strong models of PADs. ${ }^{115}$ Ulysses clauses have one controversial aspect: they are intended to be irrevocable by the patient. People who have a tendency to refuse treatment as they become unwell may want to ensure that they are able to receive services under a Ulysses clause, even if they are not detained. Whether clinicians can be bound by a Ulysses clause in a PAD, even against the contemporaneous wishes of the patient to revoke, has been widely debated. ${ }^{116}$

This issue has been debated most in the United States under the Patient Self-Determination Act (PSDA). ${ }^{117}$ In the case of Hargrave $v$ Vermont, the second circuit court held that the state of Vermont could not discriminate against individuals with psychiatric disabilities by preventing them from making binding preferences in a PAD regarding their treatment if they become incapable in the future. ${ }^{118}$ Hargrave suggested that some Courts in the United States may uphold the irrevocable nature of a PAD as a valid and binding document. ${ }^{119}$ In many of the United States templates, individuals have a choice in making their PAD revocable or irrevocable when completing the document ${ }^{120}$ and can declare that it be revoked, suspended, or terminated if the governing law permits them to do so. ${ }^{121}$

While Ulysses clauses may be enforceable in New Zealand, they are not binding against the clinician. Indeed, there is no right to demand treatment and PADs can always be overridden by the Mental Health (Compulsory Assessment and Treatment) Act 1992. Arguably, Ulysses should not be binding against the individual. Completing an advance directive does not necessarily mean that a person's decision at one point in time (when mental capacity is clear) is necessarily more important than at a subsequent point in time (during a crisis period). ${ }^{122}$ However, if an individual's past values have been recorded, along with the reasons why the

\footnotetext{
115 Jacqueline Atkinson “Ulysses' crew or Circe? - the implication of advance directives in mental health of psychiatrists" (2004) 28 Psychiatric Bulletin 3 at 3. 116 At 3

${ }^{117}$ Patient Self-Determination Act of 1991 (PSDA), Pub.L.No.101-508, 104 Stat. 1388-115, 1388-204 (1990) (codified as amended in scattered sections of 42 USC). Or look at Ambrosini at 46, footnote 55.

${ }^{118}$ Hargrave v Vermont $340 \mathrm{~F} 3 \mathrm{~d} 27$ (2d Cir 2003) [Hargrave] at 28.

119 At 38 .

${ }^{120}$ For an example of a psychiatric advance directive document that includes a revocability clause see, Bazelon Centre for Mental Health Law "Psychiatric Advance Directives"

<www.bazelon.org/publications/advanceddirectives/>.

${ }^{121}$ Bazelon Centre for Mental Health Law, above n 120.

${ }^{122}$ Widdershoven and Berghmans "Advance directives in psychiatric care: a narrative approach" (2001) 27(2) Journal of Medical Ethics 92 at 93.
} 
advance directive was completed, it is easier to see how present wishes will correspond with future goals. ${ }^{123}$

\section{B $\quad$ Treatment and Non-treatment instructions}

In this paper, the term 'treatment' is used to include the act of administering medication as well as place and method of medical performance. However, non-treatment specific directives are popular in the United States and Scotland, and non-treatment requests appear in advance care planning programmes in New Zealand. In a 2007 Scottish study of the content of personal statements, ${ }^{124}$ almost $55 \%$ of all statements included some information about nontreatment preferences. ${ }^{125}$

These examples specifically detailed past histories of mental health problems and how these had been treated successfully. ${ }^{126}$ They included information on, for example, having access to the open air which had previously helped when experiencing 'visions', or information on personal leisure interests - such as reading and choice of music - that an individual wanted staff to be aware of. ${ }^{127}$ Some request that staff should keep hold of a person's mobile phone, ${ }^{128}$ or contact family members to deal with person's finances or childcare. ${ }^{129}$

A key question is how useful a PAD which allows a wider range of information to be included. Firstly, it may be difficult to see whom it will be enforceable against (an individual or the hospital ward), and puts undue strain on mental health professionals executing them. It may help staff - especially those outside of acute care - have a better understanding of the person's overall wishes and content for treatment, but it may also make upholding the advance statement more problematic for the clinician or at a tribunal hearing. ${ }^{130}$ The inclusion of non-treatment preferences appear better placed in wellness plans such as WRAP forms. $^{131}$

\footnotetext{
${ }^{123}$ M Lanvin "Ulysses Contracts" (1986) 3(1) Journal of Applied Philosophy 89 at 92.

${ }^{124}$ J Reilly and J Atkinson "The content of mental health directives: Advance statements in Scotland" (2010) 33 International Journal of Law and Psychiatry 116.

${ }^{125}$ At 116.

${ }^{126}$ At 119 .

${ }^{127}$ At 119

${ }^{128}$ Atkinson and others "The development of potential models of advance directives in mental health care" (2003) 12(6) Journal of Mental Health 575 at 579.

${ }^{129}$ See the National Resources Center on Psychiatric Advance Directives "Getting Started" (2013) NRC PAD <www.nrc-pad.org/>.

${ }^{130}$ Reilly and Atkinson, above n 124, at 120.

${ }^{131}$ See an example of a wellness plan see appendix 4.
} 


\section{Key limitations with PAD content.}

In order for treatment preferences to be valid, they must remain within the boundaries of reasonable medical care. ${ }^{132}$ The medical community determines what constitutes reasonable care based on commonly accepted clinical practice, so that if patients record unreasonable treatment preferences in their PADs, clinicians will likely not be expected to honour such choices. $^{133}$

Other content issues which may lead to PADs not being enforced include:

- ambiguous terms/ non-treatment terms;

- terms which do not cover the patient's particular situation;

- no access to the treatment specified or the costs of using that treatment impacts in light of resource constraints.

A clinician must be able to see that the individual has considered the implications of refusing or accepting treatments. During the process of completing a PAD, it is useful for individuals to think about, and record their values and expectations affecting their current views of future medical treatment.

\section{Form of PADs}

As previously mentioned, the form of the PAD will ultimately influence the detail and length of content. When discussing the 'form' of PADs, this extends beyond simply the layout of information as a document. It encompasses 'housekeeping' procedure including the use of witnesses and formal assessment of capacity.

PAD forms vary from different clinics, even within the same jurisdiction. There is no nationally consistent PAD form in mental health services. However, the New Zealand Medical Association has an exemplar template for general (rather than mental health) advance directives ${ }^{134}$ and the Health and Disability Commissioner has a short exemplar for 'sentence structure' purposes in their brochure on PADs. ${ }^{135}$

Although the particular PAD form is not the determinative of validity, studies have shown that differences in forms have an influence in length and content that feature in PADs. Reilly

\footnotetext{
${ }^{132}$ Ambrosini, above n 12, at 15.

133 Ambrosini, above n 12, at 15.

${ }^{134}$ See appendix 3

${ }^{135}$ See appendix 2
} 
and Atkinson's 2010 study on the content of 55 advance statements in Scotland ${ }^{136}$ found that the format of the statement were not consistent and did not always conform to the templates suggested by the Scottish Executive. ${ }^{137}$ This inconsistency in the form meant that there were considerable differences in the content of the statement, from a simple single page in which consisted of "I do not want ECT" to three or four page documents outlining a wider variety of medical and personal issues. ${ }^{138}$

Requiring a strict form to be followed may put off patients from completing PADs if they see rigidity of form as an added barrier. ${ }^{139}$ However, having a standard form which specify standard questions may be helpful for those who have never made an PAD, by prompting patients and whānau to consider and document specific information which aids PAD enforcement. It is important to have sufficient information in the PAD for any enforcing clinician to determine whether the person had capacity at formation, whether the PAD was intended to cover the current scenario, and whether the patient understood consequences of their choices.

Clinicians should not refuse to consider a PAD simply because it does not accord to a standard form. But the form goes towards influencing the content in the PAD, which itself may not be enough information answer an enforcing clinician's questions.

\section{Attitudes towards PADS - a New Zealand perspective}

\section{A Methodology}

A small number of experienced mental health workers from various organisations within the Wellington Region were interviewed between August and September 2013. Seven people were interviewed in total: four were practising psychiatrists and three were consumer advocates. All had experience making or enforcing PADs. Three had mental health

\footnotetext{
${ }^{136} \mathrm{~J}$ Reilly and J Atkinson, above n 124, at 116.

${ }^{137}$ Scottish Executive The New Mental Health Act. A Guide to Advance Statements (Scottish Executive, Guidance Paper, 2004).

${ }^{138}$ Reilly and Atkinson, above n 124, at 117.

${ }^{139}$ Atkinson and others, above n 128, at 580.
} 
experience in overseas jurisdictions. ${ }^{140}$ Each interview was conducted using list of 27 prepared questions. ${ }^{141}$

The aim of the interviews was to gather qualitative analysis of some attitudes of service providers (and by their account, attitudes of patients) on PADs in the New Zealand context. It also confirmed many of the findings in PAD literature from other jurisdictions.

Interviews were deliberately conducted with these two groups of mental health workers, from two ends of the service spectrum; clinicians administer and prescribe treatment while mental health consumer advocates received patient feedback. This has highlighted some key differences in opinion on the purpose and normative legal standing of PADs.

\section{B Results}

\section{General attitudes towards PADs}

All participants were very positive about the use of PADs where appropriate. Clinicians considered PADs to be useful information sharing tools, especially when they are written to identify specific preferences. It was acknowledged by all that clinicians exercising good practice would theoretically set aside their professional beliefs when addressing a wellreasoned PAD, made by a competent patient. However, in practice, a clinician's decision is usually coloured by their own beliefs and values.

Indeed, on the other end of the spectrum, there is still a negative perception of PADs amongst some practitioners. These doctors, participants say, did not feel bound to work "under" PADs, and simply refused to consider them. Clinical apprehension towards PADs was mostly borne by the concern that PADs contain insufficient information, or that they are poorly written and do not take heed of consequences of making a treatment decision.

Clinicians interviewed mentioned that, in their experience, patients being introduced to PADs were generally receptive, but had little grasp of the time management and detail required. There was concern that, without guidance of whānau or a mental health worker, a patient trying to make a PAD alone may be put off by extensive information required.

Advocates were supportive of PADs in theory. Their experience listening to patient concerns showed that, in most cases, doctors did their best to consider the individual's views.

\footnotetext{
${ }^{140}$ Other jurisdictions included Ireland and South Africa.

${ }^{141}$ See appendix 9.
} 
However, advocates noted that the patients that perceived PADs to be futile were informed by stories of the negative experiences of other people, where competently formed PADs were ignored by the clinician or 'trumped' by the MH(CAT) Act. Many patients did not know of their right to redress if their PADs were unfairly overridden.

\section{Benefits and costs of PADs}

All participants saw the benefit of PADs as a method of information sharing. Two noted that PADs may clarify what the individual wants for themselves, which can be helpful when there are disputes between family members and there is conflicting discussion about what is in the best interest of this person who has now lost capacity. PADs were seen as the clearest form of the intention of the individual. One participant noted the humanising effect of going through the process of understanding a PAD. Clinicians are able to understand a patient's previous experiences (be it positive or negative) as told by the patient themselves.

In some cases, PADs were created as a protection tool for patients who have had a negative experience in the mental health care system. Advocates emphasised that it is difficult to know how it feels to lose certain fundamental rights when subject to compulsory care. One participant stated:

Unless you have had that kind of experience, where you lose the right to make decisions about yourself, you kind of feel that your AD is your only safeguard against unbridled power.

The fear amongst patients is that administration of treatment, and the extent to which a clinician will actually listen to their wishes, is totally dependent on that doctor's attitudes towards. Therefore, some believe PADs have the power to solidify and express to clinicians their express wishes, even if they are unable to fully communicate when ill.

Clinicians identified that the major cost of promoting PADs would be the time and resource that goes into creating a well-reasoned PAD with sufficient context. One participant noted:

Translating the quality of discussion into an $\mathrm{AD}$ is difficult and can be time consuming...very few doctors have the ability to spend time working that through. Perhaps doctors should not be the first port of call.

It was noted it would be inappropriate to recommend PADs to all patients. Many have a good relationship with their clinician, and will have a continuity of care with that clinician. PADs may do little to assist these patients, who are assured that the current clinician knows of their treatment preferences. 


\section{Content and form of PADs}

Participants noted that the content of PADs are very personal, and will vary between different patients. Nevertheless, the list of common content listed by all participants include:

- short biography of values and expectations;

- signs that indicate the person is unwell;

- the point at which the PAD should come into force;

- treatment recommendation list (prescription and dosage) and supporting reason(s);

- treatment avoidance list and supporting reason(s);

- signature of witnessing clinician or lawyer;

- signature of the patient;

- date for PAD review.

Five clinicians clearly understood the difference between a treatment PAD and a wellness recovery action plan (WRAP); ${ }^{142}$ the former specifies treatments needs and is usually used in crisis situations and the latter specifies general descriptors or wellbeing, to ensure long term good health. ${ }^{143}$ It was noted however that information such as early warning signs and triggers could feature on both forms. These clinicians clearly saw them there being synergies in the way PADs and WRAP plans could work with each other.

Interestingly, none of the participants knew whether their DHB or organisation had a premade form. Some participants thought that having some nationally endorsed prescribed forms would be helpful to guide the individual in the type of content they should include. One participant was apprehensive towards strictly applying a form, and what that would mean if an individual made a PAD outside the strict bounds of the prescribed form. It was clear there was no consistent PAD form or strategy within the Wellington Region

\section{Promoting and forming PADs}

All participants noted that consumer advocates, community mental health services, and peer support networks were the most common points in the mental health system from which service users were introduced to PADs. Most often this is when the individual has left acute services, and ready to plan for future events. This suggests that, despite concerns of undue strain on clinical time spent helping patients make PADs, community workers and peer

\footnotetext{
142 See Appendix 5.

${ }^{143}$ See Appendix 4.
} 
support by people with lived experience are more likely take up the burden of explaining the concept of PADs. Indeed, it was implied that few practising clinicians would actively recommend PADs.

The question, "who should be involved in the creation of PADs?" caused the most variation in answers. Participants unanimously agreed that the support person(s) had two key roles: first, to help the individual give reasoned answers, and secondly to attest to that person's competency at PAD formation. It is vital that this person is supporting with a therapeutic, rather than adversarial, perspective.

The list of appropriate supporting people mentioned included:

1) a clinician with sufficient knowledge about mental health treatment;

2) the individual's case worker if that is application;

3) someone outside the mental health system, who is able to attest to general capacity;

4) the patient's general practitioner. This person is likely to understand patient wellness as a whole and not just their mental state;

5) whānau and close friends should at least be informed about the PAD or given a copy.

Two clinicians agreed that it was not necessary to have a medical professional involved in PAD formation. They believed that the procedural fairness and medical rationale can be exercised by the individual with a trusted other person. However, the other five participants suggested that, to maximise the chance of having a PAD followed, it is best to have a medical professional (preferably a psychiatrist) to witness the PAD and attest to the patient's capacity.

None of the participants thought it was necessary for lawyers to be involved. One person mentioned that legal professionals could potentially shift the PAD into a contractual paradigm. This person warned against bringing a PAD outside of the therapeutic sphere:

It is where the law is inquisitorial as opposed to being adversarial. If you put together an $\mathrm{AD}$ that is adversarial, you've lost faith in your carers as being caring.

All participants noted that it was important to encourage patients to not view PADs as an adversarial document that hinders conversation with practitioners. 


\section{Monitoring PADs}

This area was not substantially discussed, but one suggestion was to have a mail alert system similar to periodic GP check-ups alerts. Provided that a copy of the PAD is kept at a patient's most frequented practice, a reminder can be sent out every year for a PAD reevaluation. The individual is able to review their PAD, make amendments, and redistribute the copies after witnessing. However, using this method, the cost of notification is borne on by the mental health system.

\section{PAD enforcement}

One main issue for clinical enforcement of PAD is access. Two clinicians admitted that they have retrospectively administered corrective treatment when it was not known at first instance that the individual had a PAD. To address this, two participants suggested that a 'yellow note' be placed the top of a patient's file alerting clinicians that an advance directive exists, and that a copy of the PAD be filed under the individual's national health index number.

The suggestion of creating a centralised database full of registered ADs was put to all participants. Clinicians were sceptical, saying that "yet another source of information storage" would be met with clinical resistance. Comparatively, consumer advocates and support workers were very adamant that a database would work and through time, collect useful information about the numbers of directives, and the types of information lodged.

The second enforcement issue clinicians mentioned was determining whether the person made the PAD with a competent mind. Moreover, two participants noted that, while an individual may lose capacity under the Act, they may, in reality, have the capacity to make decisions in crisis situations. One advocate noted:

Even though [the patient] knows exactly what they need to feel better and they communicate this with doctors, some doctors just want to give you the flavour of the day [medicine]...the "atypicals".

Each clinician was asked in what circumstances a PAD could be overridden. Major consideration included whether the individual poses a significant harm to themselves or others. It was noted that 'harm' was a relatively high threshold, and would include the risk of violence. 
Some asked whether partial fulfilment - or adherence to the spirit - of the PAD is sufficient to constitute 'enforcement'. Depending on the specificity of the PAD, partial fulfilment may be justified, especially when the PAD is difficult to follow and the clinician is doing their best to comply with the patient's requests.

Three participants suggested there should be a 'third party PAD facilitator' to guide clinicians in their decision, and to document the doctor's rationale for an enforcement decision. The facilitator would be involved when a clinician needed a second opinion to overturn an advance directive. They would also be responsible for collating these reports, and in time, develop an expertise about dealing with PADs in medical practice.

\section{Strengthening the frameworks around PADs}

While all clinicians supported the further promotion of PADs, two were against any legislative fortification of PADs. Instead, better support should be given to NGOs and peer support networks to educate individuals and their whannau about the use of PADs. All clinicians agreed that any legislative reform should still give clinicians the flexibility to make medical decisions in light of the circumstances at hand.

Consumer advocates (and presumably patients) overwhelmingly supported the strengthening of frameworks around PADs. Four participants suggested that PADs be "embedded in the MHA legislation" to give it a stronger legal status, although the finer details about how this could be achieved were not discussed. They cited two reasons: to demonstrate to patients that it is not as easy to override, and send the message to clinicians that PADs should not be lightly dismissed.

The participants who supported the third party PAD facilitator suggested an inclusion of a clause in the PAD: that "any departure from the $\mathrm{AD}$ has to have discussion and sign off by district PAD facilitators".

\section{Limitations and further research}

One key party who is missing from this dialogue is the perspective of the mental health patient themselves. Due to limited time and resources, interviewing patients was not possible in this study. ${ }^{144}$ This problem has been partly mitigated by getting the perspective of

\footnotetext{
${ }^{144}$ An Auckland University School of Nursing research team is currently conducting quantitative research on the attitudes of service providers and service users towards PADs. Initial findings to come out as soon as November 2013.
} 
consumer advocates. Consumer advocates who gather service feedback from patients can shed light on the quality of services from the patient's perspective.

Another limitation of this study is the regional scope. All but one of the participants practised in Wellington, under Wellington CCDHB. Therefore, concerns (or perhaps lack of concern) over aspects of practice may be a region-specific issue.

\section{PAD formation}

Part VI highlighted key legal and practical area in PAD formation that should be clarified for good practice in the New Zealand context. The first is ensuring that the individual has the capacity to make a PAD, and who is the best person to attest to capacity at formation. The second is to identify the role of support people; who should educate the individual about the PAD, who should help prepare it, and whether there is a need for witnesses. These two issues are interrelated. The question of who is best at determining capacity will be a major consideration in recommending roles for service providers and other support networks. The challenge for clinicians and family members is to refrain from declaring the persons incompetent to make a PAD simply because they have reached a different, and perhaps a bad, decision. $^{145}$

\section{A The Issue of Capacity to Execute}

A person who chooses to make a PAD must have the requisite capacity to make a decision about their mental health treatment. ${ }^{146}$ There was once a widespread assumption that if people were mentally ill (and especially if they were detained by reason of a mental disorder) there was no question of their having the capacity to consent (or refuse consent) to treatment. ${ }^{147}$ This is no longer correct. ${ }^{148}$ In New Zealand, the vast majority of treatment of mental illness, broadly defined, is on the basis of the patient's consent.

\footnotetext{
${ }^{145}$ Dunlap, above $\mathrm{n} 45$, at 367 .

${ }^{146}$ Code of Rights, above n 52, cl 4; Srebnik and Brodoff, above n 7, at 257.

147 Skegg and Paterson, above n 62, at [6.2.1].

${ }^{148}$ In Re S [1992] 1 NZLR 363 at 374; Re C (Adult: Refusal of Treatment) [1994] 1 WLR 290 [1994] 1 All ER 819 (Fam D).
} 
Capacity is a common law requirement. It is a necessary predicate for the valid execution of many legal transactions from wills to contracts to marriage. ${ }^{149}$ It is also an aspect of "informed consent" for treatment or refusal thereof. ${ }^{150}$

There is no all-purpose test of capacity to give or refuse consent to medical treatment. ${ }^{151}$ Even in specific context of medical procedures, the courts have not adopted one test to the exclusion of all others. ${ }^{152}$

Most tests, however, have three main elements. ${ }^{153}$ To be competent, a person must have the ability to: 1) communicate a choice; 2) understand relevant information; and 3) appreciate the situation and its likely consequences. ${ }^{154}$ Often making a PAD with a clinician may help the individual to demonstrate (2) and (3). Making it with whānau can help the patient better communicate these wishes. For completion of PADs, these abilities should be shown within two decision making areas: creating the directive itself and the substantive treatment choices specified within the document. ${ }^{155}$

Re T (Adult: Refusal of Treatment) ${ }^{156}$ concerned a Jehovah's witness who refused blood products, and provides comments about the capacity to consent which is helpful in this context. Lord Donaldson delivered the leading judgment, in the course of which he said: ${ }^{157}$

Doctors faced with a refusal of consent have to give very careful and detailed consideration to the patient's capacity to decide at the time when the decision was made. It may not be the simple case of the patient having no capacity because, for example, at that time he had hallucinations. It may be the more difficult case of a temporarily reduced capacity at the time when his decision was made. What matters is that the doctors should consider whether at the time he had a capacity which was commensurate with the gravity of the decision which he purported to make. The More serious the decision, the greater the capacity required

At the end of his judgment, Lord Donaldson MR provided a helpful summary, which included the following passage: ${ }^{158}$

\footnotetext{
${ }^{149}$ Skegg and Paterson, above n 62, at [6.2.1].

${ }^{150}$ At [6.2.1].

${ }^{151}$ Srebnik and Kim "Competency for Creation, Use, and Revocation of Psychiatric Advance Directives" (2006)

$34 \mathrm{~J}$ Am Acad Psychiatry Law 501 at 502.

152 Skegg and Paterson, above n 62, at [6.2.1].

${ }^{153}$ Dunlap above $\mathrm{n} 45$, at 367.

154 Jessica Berg and others "Constructing Competence: Formulating Standards of Legal Competence to Make Medical Decisions (1996) 48 Rutgers L Rev 345 at 352 - 53; Srebnik and Kim, above n 151, at 503.

155 Srebnik and Kim, above n 151, at 503 .

${ }^{156}$ Re T (Adult: Refusal of Treatment) [1993] Fam 95; [1992] 4 All ER 649 (CA).

${ }^{157}$ At 113.
} 
Doctors faced with a refusal of consent have to give very careful and detailed consideration to what was the patient's capacity to decide at the time when the decision was made. It may not be a case of capacity or no capacity. It may be a case of reduced capacity. What matters is whether at the time the patient's capacity was reduced below the levels needed in the case of a refusal of the importance, for refusals can vary in importance.

This passage acknowledges that there can be levels of capacity, and the potential to have reduced capacity but not lose it entirely. The provision in the Consumer Code of Rights is consistent with Lord Donaldson MR's view that capacity is not an all or nothing matter. Right 7(3) provides that where a consumer has diminished competency, that consumer retains the right to make informed choices and give informed consent, to the extent appropriate to his or her level of competence.

The capacity required will change with the gravity of the situation. In the case of advance directives for end of life situations, the refusal of treatment can have serious and irreversible consequences (usually the advancement of death). Therefore a high level of competence is required to fully appreciate the consequences. ${ }^{159}$ By comparison, the consequences of refusal or acceptance of treatment in mental health may not have such an immediate and serious consequence because there is scope for the individual to get better. ${ }^{160}$ Usually refusal of treatment is very specific - identifying particular medications that the person would not want.

The converse may be true, if the individual refuses the lynchpin treatment which will put the individual in a position to recover. For example, a person suffering from anorexia who makes a PAD refusing future treatment involving force feeding could in fact die if her PAD is adhered to. In such cases, capacity must be measured against this more serious consequence.

Some feel concern that the level of competency required to form PADs are "overblown"161 and it should be noted that many physical illnesses (e.g. multiple sclerosis, AIDs, dementia) may affect cognitive capacity in ways similar to mental illness. ${ }^{162}$ Advocates note that it is important not to create a different standard of competency for mental health consumers from others attempting to create health care ADs. ${ }^{163}$

\footnotetext{
${ }^{158}$ At 116.

${ }^{159}$ Dunlap, above n 45, at 368 .

${ }^{160}$ Papageorgiou and others, above n 22, at 385.

${ }^{161}$ Dunlap, above $\mathrm{n} 45$, at 327.

162 Okai and others "Mental Capacity in Psychiatric Patients: Systemic Review?" (2007) 191 The British Journal of Psychiatry 291 at 293; MacArthur Research Network "The MacArthur Treatment Competence Study" (2004) MacArthur Research Network on Mental Health and Law <www.macarthur.virginia.edu/treatment.html>.

${ }^{163}$ Srebnik and Kim, above n 151, at 505 .
} 
Because often the question of competency and insight into the consequences of treatment is not a clear-cut issue and the inquiry is after the fact (of PAD formation), it is important to have people who can verify the competency of the individual at the time of formation. However, as the current practice stands, the parties attesting to a person's competency are not always medical professionals nor legal professionals, and this may cause evidentiary and legitimacy issues.

\section{B Parties to be Involved in PAD Execution}

\section{Clinicians and Service Providers}

Clinical advice given at the time the patient completes a PAD has benefits and disadvantages. On the one hand, it is important that consumers have sufficient information about health care treatments when they executed the PADs. ${ }^{164}$ The fear is that a patient might not be fully informed about treatment options, particularly if PADs are completed outside of a clinical context. This may lead to more unreasonable requests. Mental health service provider input will better ensure that individuals understand the full consequences (or clinical result) of their decision, and still keeping within the realms of good practice. Service providers may be able to anticipate additional medical circumstances for prior planning that a patient themselves may not think of otherwise.

The importance of clinical involvement in formation is evident in literature and the interviews conducted for this paper. Some clinicians would not apply a PAD unless the individual has had consultation with a service provider. ${ }^{165}$ In a United States PAD survey, $92 \%$ of clinicians reported that it would be "somewhat", "very", or "extremely" useful to have service providers help consumers execute the PAD. ${ }^{166}$ In the interviews conducted with New Zealand clinicians in this paper, five of the seven participants agreed that clinical involvement would maximise the chance of having a PAD enforced. ${ }^{167}$

\footnotetext{
${ }^{164}$ Srebnik and Brodoff, above n 7, at 257.

165 At 258

166 At 258.

${ }^{167}$ See Part VI 'Promoting and forming PADs'.
} 
On the other hand, a contentious question is the level of involvement service providers should have in PAD formation. There is a concern that clinicians might unduly influence the process or undermine consumer choice. ${ }^{168}$

Whether it should always be necessary to have patients create advance directives with clinicians, and if so, what role within the formation process are harder questions to answer. Psychiatrists in particular have expressed a reluctance to spend significant time constructing PADs with consumers in a public health system, where their valuable time should be spread fairly amongst treating other patients for more urgent matters. ${ }^{169}$

In the United States, the Patient Self Determination Act requires that patients admitted to federally funded hospitals be informed about their right under state law to prepare an advance directive. ${ }^{170}$ But, to put the same onus on service providers to explain the workings of a PAD to every patient who is admitted to public hospitals in New Zealand is neither practical nor a good use of service provider time.

\section{Consumer Advocates and Peer Support Networks}

Despite the potential advantage of clinician involvement in legitimising the PAD, an interesting finding from the interviews conducted for this paper is that many service users created PADs at the instigation and in collaboration with consumer advocates and peer support networks, rather than clinicians. ${ }^{171}$

Consumer advocates work for regional DHBs, advising patients of their rights, listening to their needs and provide consumer feedback to DHB planning. ${ }^{172}$ There are also an array of mental health support services outside of inpatient care, that cater to supporting individuals and their families in the community with mental health care planning. ${ }^{173}$ Additionally, peer support services in mental health involve networks of people who have experienced similar

\footnotetext{
${ }^{168}$ Srebnik and Brodoff, above n 7, at 258; supported by confidential interview with consumer advocate, 4 September 2013.

${ }^{169}$ See Part VI 'Promoting and forming PADs'.

${ }^{170}$ Patient Self-Determination Act of 1991 Pub L No 101-508, § 489.102, 104 Stat 115 at 204 (1990).

${ }^{171}$ See Part VI 'Promoting and forming PADs'.

${ }^{172}$ Mental Health Foundation "Consumer/Tangata Whaiora Networks" (2013) Mental Health Foundation Website < www.mentalhealth.org.nz>.

${ }^{173}$ Mental Health Foundation, above 172.
} 
adversity, who provide advice to other service users to plan before crisis, for sustained wellbeing. ${ }^{174}$

Axiomatically, these three groups of people are better poised than clinician to promote PADs to patients. They tend to have more time to spend with mental health patients on the quality of their care. While direct service providers may be strained by key performance indicators (including incentives to moving individuals to outpatient care), advocates' main role is to better understand the patient's needs and preferences and communicate these needs to better inform service providers. ${ }^{175}$

Additionally, advocates and social workers have the ability to hear from a greater population of patients about quality of care, and identify general patterns in patient satisfaction. They specialise in understanding the holistic needs of patients, not just the medically treat the outward manifestations. Some patients simply do not feel comfortable criticising the practice of clinicians to their own clinician. ${ }^{176}$ Patients may feel more comfortable confiding in and discussing PAD content with advocates and social, because they are not required to treat the individual.

Peer support networks are particularly influential on current service users. Peers have lived through similar experiences and are trained to educate others. ${ }^{177}$ The advice to make a PAD and the rationale for doing so is more insightful coming from a person who can truly empathise with the patient's experiences. This insight is heightened if the individual has had their PAD upheld in a positive experience, reinforcing the power PADs have in giving patient voice a platform to be heard.

\section{The Role of the Family and Whānau}

The other group of people who are most likely to understand a patient's experience with mental health treatment is close family and whānau. Family members are the most often quoted emergency contact, and can often see the signs of a person becoming unwell better than any clinician.

\footnotetext{
${ }^{174}$ The Mental Health Commission "Power of Peer Support Services in Mental Health and Addiction" Mental Health Commission <www.hdc.org.nz > at 2.

175 The Mental Health Commission, above n 174.

${ }^{176}$ Confidential interview with a consumer advocate, 30 September 2013.

177 "Peer Network: A Definition" (2013) NZ Peer Support Network < peersupport.net.nz/resources/what-do-wedo>.
} 
The HDC brochure on making mental health ADs recommends the involvement of family and whānau when preparing advance directives, or at least informing them of it so that they are better equipped to voice the individual's wishes in a crisis. ${ }^{178}$ In many enquiries after a patient's death or some alleged misconduct, it has been the evidence of whānau that attests to the patient's capacity. However, being reliant on family members to highlight the importance of a PAD is not always effective. There have been stories where parents of a mentally unwell patient who had an advance directive omitted to bring the PAD to the attention of the doctor, having presumed that the doctor had already read the PAD. ${ }^{179}$

Whānau input may be particularly important for the therapeutic process of Māori mental health patients. The Te Whare Tapa Whā, a model for understanding facets of Māori health, was developed by Professor Mason Durie recognises four components to Māori health, one of which is for whānau to play an important role in the wellbeing of a person. ${ }^{180}$ Whānau can contribute to sickness as well as assisting in curing illness. ${ }^{181}$ The sense of belonging and strength that whānau provide - especially in the acceptance and understanding of a person's advance directive - is a key foundation of Māori health. ${ }^{182}$ This cooperative agreement may explicitly involve the specification of family members who may be contacted if the PAD is invoked, or if the PAD is changed with a clinician. ${ }^{183}$

\section{Witnessing PADs}

In the United States and Scottish jurisdictions, it is generally expected that an advance statement will be witnessed. In New Zealand, a valid will must be witnessed by at least two people. ${ }^{184}$ In the medical context, the key question is whether the witness is attesting to the capacity of the person making the advance directive (and how formal this assessment is) or simply that the person made the advance directive themselves. ${ }^{185}$

Where the witness is attesting to the capacity of the person, it is important that the said person has the requisite knowledge to recognise capacity. The guidelines to the Scottish Act prescribes a list medical and legal professions deemed acceptable witnesses, including such

\footnotetext{
${ }^{178}$ Health and Disability Commissioner, above $\mathrm{n} 59$.

${ }^{179}$ Interview with a psychiatrist, 2 October 2013.

${ }^{180}$ Mason Durie Maori Health Development (Oxford University Press, Auckland, 1994) at 68.

181 At 69.

182 Joanne Baxter and Rees Tapsell "Recognising and Managing mental health disorders in Maori" (2010) Best Practice Journal New Zealand 28 at 14.

${ }^{183}$ See appendix 3.

${ }^{184}$ Wills Act 2007, s 11(4)-(5).

185 Atkinson, above n 16, at 143.
} 
as doctors, nurses, solicitors, and social service worker. ${ }^{186}$ The position of the witness is described to the person making the advance statement as "...confirming that in their opinion you are able to understand what you have written in the statement and the effect it might have on your future treatment."187

Witnessing could be seen as a limited approach to attesting capacity. ${ }^{188}$ In the Scottish system, it is assumed that both medical and legal professionals are able to attest capacity, even though the two may apply tests with a different focus. ${ }^{189}$ Without any consistent guide, the way that a clinician assessment competency could medical-centric, while a lawyer focuses on ability to understand their own decisions. ${ }^{190}$ Although the end result may not be different, the competency to execute test should be clarified in either guidelines or statute.

The Scottish system clarifies that, while the witness must ensure the patient has considered their choices, that person does not have to be involved in writing of the advance directive. Nor does the person need to agree with the individual's choice. ${ }^{191}$ These two points are likely to be important to patients as they emphasise the independent nature of the PAD. The professional asked to witness a PAD should also feel more comfortable if the directive goes against what they would advise or see as best practice.

\section{Conclusion}

In the New Zealand context, in light of both clinical concern whether PADs are made with sufficient patient awareness of consequences, as well as scepticism as to whether clinician's time is best used to educate the patient about PADs, requiring that a clinician or social worker witness the advance directive for capacity seems a good half-way solution. Clinical agreement with the treatments specified need only extend to acknowledging that treatment is still within good medical practice, even though the clinician may not think it is the most effective treatment. Taking away the conscience element widens the scope of potential clinicians who are able to witness. A definition of 'clinician' should be made in legislation or formal guidelines. ${ }^{192}$

\footnotetext{
${ }^{186}$ Scottish Executive, above n 137 , at 8 .

187 At 8 .

${ }^{188}$ Atkinson, above n 16, at 143.

189 At 146

${ }^{190}$ Srebnik and Kim, at n 151, at 503.

${ }^{191}$ Scottish Executive, above n 137, at 8.

192 See Part X: Key Recommendations.
} 


\section{Storage and Monitoring PADs}

\section{A Storage and access}

PAD which cannot be accessed at a crisis point, or which no one knows exists, is not worth the paper it is written on. ${ }^{193}$ Having PADs housed within after-hours services and outpatient medical records is to be a minimum required for accessibility.

The complexities of accessing PADs in crises time are corroborated in literature, demonstrating that health care advance directives are accessed by staff in only about one third of cases. ${ }^{194}$ In a study of 161 service-users in the England, over half did not remember what had come of the PAD only a year after making it. ${ }^{195}$ A good access system should not rely on an ill patient to raise the existence of a PAD. However, a patient is able to help ensure that their PAD is stored in places or with people that can raise it in a crisis. ${ }^{196}$

\section{Who should be informed?}

Scottish Advance Statement Guide provides a fairly extensive list of people to whom a copy of the AD should be given. This covers, where they exist, a named person, carer, family, solicitor, nurse, independent advocate, guardian, welfare attorney, responsible medical officer, mental health officer, general practitioner, and other people close to you. ${ }^{197}$ The advantage of giving your PAD to an extensive list of people is that, the more people who have a copy, the easier it might be to access it when it is needed. ${ }^{198}$ Information privacy issues caused by a widespread dissemination may be avoided if whanau know where the PAD is kept rather than holding a copy at all times. ${ }^{199}$

\section{Electronic Health Records (EHR)}

An obvious place to indicate the existence of a PAD would be at the front of the patient's medical records in the EHR, which prompts the clinician to read further into the individual's medical notes. $^{200}$ An enhancement of this feature would be if the computerised record not

\footnotetext{
193 Srebnik and Brodoff, above n 7, at 256.

${ }^{194}$ Danis and others "A prospective study of advance directives for life-sustaining care" (1991) 324 New

England Journal of Medicine 882, at 884.

${ }_{195}$ Papageorgiou and others, above n 22, at 386.

${ }^{196}$ Srebnik and Brodoff, above n 7, at 257.

${ }^{197}$ Scottish Executive, above n 137, at 10.

${ }^{198}$ Atkinson, above n 16, at 146.

199 At 147.

${ }^{200}$ Papageorgiou and others, above n 22, at 386.
} 
only flags up an advance directive at the outset, but also requires confirmation that this had been noted. ${ }^{201}$ It could be amended to require consultation before hospitalisation or before compulsory measures are taken.

However, a barrier to strengthening access to PAD highlighted in Part VI is the difficulty of inputting and removing information from the EHR system. Currently only certain clinicians within the DHB system is able to add and remove information on patient's NHI record. Furthermore, the clinical access between regional DHBs still causes problem as DHBs have different operating systems. ${ }^{202}$ Ideally, an EHR would be distributed across all health settings and be centred on the person, rather than being a series of isolated information repositories located within various health care agencies. ${ }^{203}$ In the current position, individual DHBs would have to be proactive in lodging PADs onto the register, or alternatively the Ministry of Health would have to make a big effort to centralise the access of information. ${ }^{204}$

\section{$B \quad$ Reviewing and changing PADs}

While a PAD may represent the competent wishes of patient at one point in time, this is subject to a change of mind. ${ }^{205}$ A patient may have since been treated with more effective medication, their values and expectations have changed, or their physical health may have altered. $^{206}$ All of these factors may mean that the PAD is no relevant to the patient in their current health. Even if preferences have not changed, it is important for the acting clinician to be sure of this, especially if a clinician is put in a position where a decision has to be made about whether to follow a directive that was made some time ago. Without frequent review, a clinician may be justified in overriding a PAD. Any legislative or 'good-practice' guidance for making PADs should encourage individuals to review PADs and set a defined renewal date (for example, every five years). ${ }^{207}$

\footnotetext{
${ }^{201}$ Atkinson, above n 16, at 146.

${ }^{202}$ Confidential interview with a psychiatrist, 22 August 2013.

${ }^{203}$ Wayne Naylor Sharing Patient Health Information: A review of health information privacy and electronic health records in New Zealand (Palliative Care Council of New Zealand, May 2010) at 2.

${ }^{204}$ Srebnik and Brodoff, above $\mathrm{n}$ 7, at 256.

${ }^{205}$ Srebnik and Kim, above n 151, at 506.

206 At 506.

${ }^{207}$ Srebnik and Brodoff, above $\mathrm{n} 7$, at 259 . The cost a system reminding service users to renew is discussed in Part VI above.
} 
This section discusses some of the more difficult philo-ethical and legal issues surrounding PAD enforcement by service providers. Again the issue of capacity is central to when a PAD is invoked. This can create a tension when there is subsequent express revocation, and the clinician's moral and ethical judgements are tested. A 'good practice' guideline will develop a transparent decision-making procedure for clinicians, that both service users' and service providers' trust, and can be applied consistently. In doing so, legislators should understand that PADs are nested in larger structures of mental health law and policy that protect the interests of parties other than the patient. ${ }^{208}$

\section{A When is a PAD invoked?}

When to invoke or activate a PAD is not always a straightforward procedure. In the eyes of the law, a person is presumed to have capacity unless legally declared otherwise, ${ }^{209}$ or unless good cause can be shown for presuming otherwise to allow, for example, emergency treatment. $^{210}$ Thus, invoking a PAD necessarily means that a judgement about capacity has to be made.

In New Zealand, the Code of Consumer Rights cl 4 states an advance directive is intended to be effective only when he or she is not competent. In some jurisdictions, PADs are invoked when a person falls within the Mental Health Act (even though this is usually the same as saying someone lacks capacity to make treatment decisions). In Scotland, for example, once a patient comes under the provisions of the Mental Health (Care and treatment) Scotland Act 2003 , account has to be taken of any existing advance statement. ${ }^{211}$

The quandary about when to activate PADs raises a broader question about the purpose of PADs: are they used to help de-escalate crises and provide alternatives to outpatient commitment and hospitalisation, or are they to be implemented only under the limited circumstances of legal incompetency? ${ }^{212}$

\footnotetext{
${ }^{208}$ Swanson and others, above n 10 , at 385 .

${ }^{209}$ Code of Rights, above n 52, Right 7(2).

${ }^{210}$ Atkinson, above n 16, at 147.

${ }^{211}$ Mental Health (Care and Treatment) (Scotland) Act 2003, s 276(3).

${ }^{212}$ Atkinson, above n 16, at 148.
} 
Activation of PADs early in a mental health crisis can be invaluable to medical staff as a guide to appropriate and desired care. ${ }^{213}$ In this way, PADs would be used in the same manner as a crisis plan. ${ }^{214}$ Some advocates agree and would like PADs to be activated early enough to provide treatment to individuals who show signs of decompensation, but who nevertheless "fall through the cracks," neither actively participating in voluntary treatment nor meeting criteria for involuntary treatment. ${ }^{215}$ If the aim of the PAD is to provide early treatment (which might be refused) to prevent or de-escalate a crisis, then the "loss of capacity' threshold for invoking the PAD might be set lower.

However, given the presumption of capacity to refuse treatment, a more formal capacity assessment should be made before a PAD is activated. Many psychiatrists appear unwilling to declare a patient incapable unless detention, guardianship or similar circumstances exist. ${ }^{216}$ This formal approach to invoking a PAD is likely to reduce their use, and this usefulness in promoting patient choice and autonomy

This may be further complicated if the PAD covers more than just medical treatment. Patients may be impaired in making a decision about their clinical care, but capable of making other decisions. Although this will only cause practical problems if decisions in the advance directive differ from current decisions, it cannot be optimal or in accordance with the least restrictive alternative, to be using the PAD where it is not necessary. ${ }^{217}$ Yet to argue for only invoking parts of it is likely to be problematic.

Any best practice guideline needs to give clinicians clear direction to determine when capacity is lost, and specify whether the capacity requirement is the same as that to execute a will.

\footnotetext{
${ }^{213}$ J Ritchie, R Sklar, and W Steiner “Advance directives in psychiatry” (1998) 21 International Journal of Law and Psychiatry 245 at 250.

${ }^{214}$ Swanson and others "Psychiatric advance directives: an alternative to coercive treatment? (2000) 63 Psychiatry 160 at 163.

${ }^{215}$ G Sales "The health care proxy for mental illness: can it work and should we want it?" (1993) 21 Bulletin of the American Academy of Psychiatry and the Law 161 at 171.

${ }^{216}$ Atkinson, above n 16, at 149.

${ }^{217}$ At 150.
} 
When an advance directive is brought to the attention of a treating psychiatrist, there should be a positive obligation at the minimum to explore the reasons for such prior content wishes. $^{218}$

There is no gold standard of when it is acceptable to override a competent person's wishes in an advance directive with impunity. ${ }^{219}$ Doctors are under no obligation to follow an advance directive to which they hold a conscientious objection or see the action as unethical. ${ }^{220}$ In such a circumstance, the doctor should explain to the medical team involved, and any pointed surrogate decision maker, why they are not willing to follow the PAD. ${ }^{221}$

Brock $^{222}$ has outlined three general types of scenarios in which clinicians might consider overriding a general ADs: 1) when there is doubt that the $\mathrm{AD}$ accurately reflects what the patient would have wanted, 2) when the moral authority of the advance directive is questionable due to concurrent revocation, and 3) when the interests of persons other than the patient warrant overriding the directive. The next section considers whether these scenarios may be proper justifications for overriding ADs in the psychiatric context.

\section{$1 \quad$ PAD reflect patient wishes?}

From the perspective of patients with a long history of psychiatric treatment, PADs convey treatment preferences much more accurately than medical ADs used in end of life situations, as it is often written in light of previous treatment experiences. Rather, a more pressing problem for clinicians is when the PAD contains insufficient information to show that the person considered the particular circumstance at hand. ${ }^{223}$ This suggests the importance of a framework at formation which promotes the articulation of explanation for treatment decisions. $^{224}$

There have been doubts raised particularly in the case of patients who refused ECT in a PAD, but have never themselves experienced ECT. ${ }^{225}$ In the scenario where a patient falls into a

\footnotetext{
218 Ambrosini, above n 12, at 51.

${ }^{219}$ Srebnik and Kim, above n 151, at 502; Sorem Holm "Autonomy, Authenticity, or Best Interest: Everyday Decision-Making and Persons with Dementia" (2003) 4(2) Medicine, Health Care and Philosophy 153 at 155 F. ${ }^{220}$ New Zealand Medical Association, above n 43, at [11].

221 At [11].

${ }^{222}$ Dan Brock "Trumping Advance Directives" (1991) 21(5) The Hastings Center Report S5 at S5.

${ }^{223}$ Srebnik and Brodoff, above n 7, at 260; New Zealand Medical Association, above n 43, at [10(a)].

${ }^{224}$ Srebnik and Brodoff, above n 7, at 260.

${ }^{225}$ Swanson and others, above n 10, at 388.
} 
catatonic state from extreme depression (something the patient never expected to happen, even in a worst-case scenario), ${ }^{226}$ clinicians have been justified in treating the patient with ECT, where it is a last resort to save their life. It presumes that a patient's wishes would never be to die as a result of not receiving treatment.

This issue can also be alleviated if there is enough general information about the patient's values and expectations within the PAD, so that a clinician can try and uphold a patient's treatment decisions wherever possible and if it is consistent with their stated values. ${ }^{227}$ In this case, the PAD stands as the best evidence of what the consumer would have chosen for treatment if competent. ${ }^{228}$

\section{Patient current revocation of a valid PAD}

A further complication for clinicians occurs if the patient, who is now ill and lacks requisite capacity, revokes what was specified in their PAD. For example a person who suffers from anorexia may refuse to be force fed in an acute situation, even though her PAD has specifically agreed to force-feeding treatment in a crisis scenario. ${ }^{229}$

Revocation is particularly problematic in areas of psychiatric treatment. Cases of revocation of an $\mathrm{AD}$ which is enacted in general health care crises are rare because usually the person is unable to communicate, or may be out of consciousness altogether (in end-of-life scenarios). The 'blurriness' in the revocability of mental health advance directive at crisis point occurs partly because the power to make a PAD is implicit in the Code of Rights allowing the making of general advance directive. In PAD revocation cases, whether to enforce treatment against a currently refusing patient who is incapable of revoking is difficult to determine. ${ }^{230}$

The New Zealand law requires consumers to be competent or have capacity in order to make an advance directive. It is a fair inference to draw that competence again is needed to change an advance directive. ${ }^{231}$ However, doctors are uneasy about "enforcing" the preferences

\footnotetext{
${ }^{226}$ Confidential interview with a consumer advocate, 30 September 2013.

${ }^{227}$ Swanson and others, above n 10, at 386.

${ }^{228}$ E Gallagher "Advance directives for psychiatric care: a theoretical and practical overview for legal professionals" (1998) 4 Psychology, Public Policy and Law 746 at 747.

${ }^{229}$ Anecdotal story from confidential interview with a psychiatrist, 22 August 2013.

${ }^{230}$ Atkinson, above n 16, at 151.

${ }^{231}$ Winick, above n 30, at 62; Atkinson, above n 16, at 152.
} 
specified in a PAD against the contemporaneous revocation of those preferences. ${ }^{232}$ Such enforcement could lead to coercion and uncooperative treatment. ${ }^{233}$

(a) Revocation of an opt-out provision

Where the person has opted out of certain treatment and then changes their mind, clinicians may be happy to accept this, possibly choosing to see it as the beginning of a return to capacity. $^{234}$ In most cases clinicians are likely to follow patients' choices where they opt for treatment and maintaining and preserving health and life than not.

To draw a comparison, women with advance directive birth plans routinely change their minds during labour. Birth plans made by pregnant women often request 'natural child birth' and no medication for pain. However it is not uncommon for women to change their minds during labour and request pain relief. ${ }^{235}$ This is given, and to most people it would be inconceivable for the doctor or midwife to say to the woman "several months ago you said you didn't want pain relief so you're not getting it". It is despite the fact that everybody understands that pain has a clear impact on judgement and ability to make rational decisions.

However, the legitimacy of a revocation might be questioned when it is not expressed as an active request but more in the form of an "I don't care anymore" mentality to treatment, prevalent in patients worn down by illness and possible pressure from clinicians, family and friends. $^{236}$

(b) Revocation of an opt-in provision

A more likely scenario is for the patient to revoke an opt-in provision. Deciding whether to uphold the revocation is even more difficult. There is concern that the revocation is a symptom of the mental illness, and is the exactly the reason for which the PAD was written. ${ }^{237}$ A Ulysses clause is an example where the individual specifically seeks to make their wishes irrevocable. ${ }^{238}$

Consideration must be given to the reasons why the individual included the opt-in clause in the first place; a nuanced exercise. If it was to self-bind, like a Ulysses clause, so as to

\footnotetext{
${ }^{232}$ Swanson and others, above n 214, at 391.

${ }^{233}$ Srebnik and Brodoff, above n 7, at 261.

${ }^{234}$ Atkinson, above n 16, at 150.

${ }^{235}$ At 151 .

${ }^{236}$ At 150

${ }^{237}$ Srebnik and Kim, above n 151, at 507.

${ }^{238}$ Atkinson, above n 115, at 3.
} 
deliberately ignore the irrational behaviour when ill, then this seems to suggest that it would be in the best interest of the individual for doctors to adhere to the PAD against an express revocation. If it was a general early opt-in for treatment to pre-empt worsening of the person's mental state, then perhaps revocation should still be respected when the person loses capacity.

Winick proposes that consumers should be able to choose whether they want a PAD that could be revoked at any time or only when not considered to be incapable. ${ }^{239}$ It has been suggested that they should also make a statement about whether they can revoke it at any time, or only when they are capable. ${ }^{240}$

Others argue self-binding PADs could be worded in a way to require serious intervening factors before a doctor can override, including the significant risk of serious harm to self and others. $^{241}$ This was certainly the view of Wellington clinicians interviewed, who believed an absolutely binding PAD may cause problems if it is not in line with good clinical care. ${ }^{242}$

\section{Protecting the interests of others}

Brock raises the quintessential example to demonstrate this dilemma: the interests of a patient near death have substantially diminished and interests of the family are the driving force in medical decision-making - a phenomenon colloquially known as "treating the family". 243 For example a clinician may refused to apply an opt-in PAD in cases where the clinician believes this treatment will be psychologically futile, yet the patient and the family demands it. $^{244}$

An extension of this argument is one on the basis of distributive justice: that it is unfair to expend scarce medical resources on futile care for one patient merely because the patient requests such care in advance. ${ }^{245}$ The opponents of the court's decision in Hargrave $v$ Vermont have argued that, priority should have been given to the larger interests of society in this matter - for example, the interests of the taxpayer who might ultimately have to pay for

\footnotetext{
${ }^{239}$ Winick, above n 30, at 57.

${ }^{240}$ Atkinson, above n 16, at 152.

${ }^{241}$ Swanson and others, above n 10, at 388.

${ }^{242}$ See discussion in Part VI.

${ }^{243}$ Brock, above n 222, at S6.

${ }^{244}$ At S6.

${ }^{245}$ Swanson and others, above n 10 , at 389.
} 
longer hospital stays for psychiatric patients with PADs that refuse antipsychotic medications. ${ }^{246}$

While the interests of the family and other patients (indirectly through distribution of resources) must be taken into account when deciding whether to revoke a PAD, they should not be held as determinative factors for overriding PADs. It is important that we give clinicians the flexibility to balance factors and exercise their better professional judgement.

\section{Key Recommendations}

\section{A Legislative Amendments}

From the interview discussions in Part VI, it was clear that advocates and patients wanted the "legal standing" of PADs strengthened. What this could mean has not been elucidated until now. Any strengthening of legal standing must take heed of two issues. Pertinently, clinicians make hard decisions on a day-to-day basis, and are personally accountable for the outcome. Therefore, a doctor should be under no absolute legal obligation to follow an advance directive which is inconsistent with good medical practice. ${ }^{247}$ If absolute legal obligation is put into such a written document, a doctor may be forced to take responsibility for following a PAD against their better judgment. ${ }^{248}$

Furthermore, it may not be possible for a clinician to follow an advance directive if certain circumstance that existed at the time the PAD was made has changed, or if the PAD is not worded in a way that considers the particular circumstance at hand. Therefore, the legal structure must be able to give clinical flexibility to exercise good judgement.

This is balanced with the policy of promoting patient participation, even if they are subject to compulsory treatment under the MH (CAT) Act. As noted in Part VI, ${ }^{249}$ this is particularly important given that patient's request (and the capacity to make requests) is questioned as soon as they are deemed "mentally disordered" 250 and require treatment against their will.

\footnotetext{
${ }^{246}$ Hargrave, above n 118, at 33.

${ }^{247}$ New Zealand Medical Association, above n 43, at [10(c)].

${ }^{248}$ Swanson and others, above n 10, at 392.

${ }^{249}$ See Part VI 'General attitudes towards PADs'.

${ }^{250}$ Under the Mental Health (Compulsory Assessment and Treatment) Act 1992.
} 


\section{Right to have PADs considered}

With the two tensions above in mind, it is proposed that a section requiring the consideration of PADs be included in the MH(CAT) Act 1992. This could be achieved with an additional section to the 'rights of patients' under Part $6 .{ }^{251}$ Similar to the Scottish Model, this section would make it a right for all patients to have their wishes considered by the treating clinician, if attention is raised to the existence of an advanced directive. ${ }^{252}$ This right would apply for urgent emergency treatment as well as compulsory treatment orders. ${ }^{253}$ In addition, a clinician should be required to explain to the patient, as well as have in written record, the reasons for overriding a PAD. ${ }^{254}$

Placement of this section under the MH(CAT) Act is important for two reasons. Facially, it clarifies that $\mathrm{ADs}$ in the realm of mental health will be given validity. Until now, validity has only been presumed under the provision for general medical advance directives in the Code of Rights. Moreover, it recognises that, in most cases, a PAD would only come into force when a person loses capacity, and there is a need to administer compulsory treatment or certain emergency treatment. ${ }^{255}$ It addresses the misconceived opinion that clinicians do not need to consider PADs if a patient is under the MH(CAT) Act. ${ }^{256}$

Substantially, the 'right for PADs to be consideration' strikes a balance between ensuring patient's wishes are heard, but also allowing that clinicians the room to override the PAD when it is not in good practice to follow it. The documentation requirements ensure that clinicians do not lightly override a patient's will and think through alternatives, while simultaneously protecting clinicians who makes a sensible judgement call to give treatment to save the life of a patient. Having sufficient records also ensures evidentiary transparency for the patient.

Holistically, the inclusion of this right will serve as a catalyst - or a 'top-down' approach - to encourage DHB and external mental health services to develop a long-term PAD strategy. If it is a patient right under the $\mathrm{MH}(\mathrm{CAT})$ Act, its consideration must be integrated into the practice of service providers. This directly addresses the problem that it is not common

\footnotetext{
${ }^{251}$ Mental Health (Compulsory Assessment and Treatment) Act 1992, Part 6.

${ }^{252}$ See appendix 1.

${ }^{253}$ See appendix 1.

${ }^{254}$ See appendix 1.

${ }^{255}$ Mental Health (Compulsory Assessment and Treatment) Act 1992, s 110.

${ }^{256}$ An issue raised in Part VI 'General attitudes towards PADs'.
} 
practice for clinicians to inquire whether a patient had a PAD when they first entered the DHB system. ${ }^{257}$

\section{Redress under the $M H(C A T)$ Act}

If a patient believes that a clinician has disregarded their PAD without proper reason, there can be redress under the $\mathrm{MH}(\mathrm{CAT})$ Act. This would be a separate form of redress, from what can already be addressed through the complaints process under the Health and Disability Commissioner Act 1994, ${ }^{258}$ and complaints under the Human Rights Commission. ${ }^{259}$

\section{External PAD facilitator}

Many of the clinicians interviewed under Part IV discussed the usefulness of having a PAD facilitator that specialised in the implementation of PADs in medical practice. A facilitator would be employed by the DHB and have three key roles: to oversee the PAD process and give a second opinion if requested; to write up a report when a PAD is not followed; and to collect reports and synthesise patterns to develop clinical guidance. In order to give a second opinion, the facilitator must himself be a clinician with mental health service experience. However, the decision to administer or not administer treatment against the wishes of a PAD would ultimately be made by the treating clinician. Given current resource strains, the creation of an external PAD facilitator would be a best case scenario.

\section{B Education and PAD Support Programme}

Legislating for the consideration of PADs by clinicians in a 'top-down' approach addresses issues of enforcement and access to an extent. However, to achieve cultural and systemic change in the perception of PADs, this needs to be supplemented by a 'bottom-up' approach by providing education and guidelines to service providers and service users.

\section{Guidance for clinicians and legal professionals}

The Ministry of Health should supplement the legislative amendments with a 'good practice' guideline. This should be specifically targeted at clinicians (and witnessing lawyers), and outline clear directions to determine capacity and when capacity is lost. It should be made

\footnotetext{
${ }^{257}$ See Part VI 'PAD enforcement'.

${ }^{258}$ Health and Disability Commissioner "Complaints Resolution Overview” (2013) Health and Disability Commissioner Website < www.hdc.org.nz>.

${ }^{259}$ Human Rights Commission Resolving discrimination and harassment: a guide to making and responding to a complaint under the Human Rights Act 1993 (Human Rights Commission, Guidance Paper, October 2010).
} 
clear that practitioners do not have to agree with the treatment preference specified. It should also specify exemplary procedures to follow if there is PAD enforcement issues such as revocation.

\section{Support for service users and their whānau}

The Ministry of Health must update their pamphlet to include a good practice PAD template. While easy to follow information on PADs already exists on the website, the importance of the following PAD content should be stressed:

- the scope and good-faith spirit of a PAD;

- that while PADs do not have to be made with anyone other than the patient, making PADs with other trusted people will give the service user the best chance of having it enforced;

- that all treatment preferences should include sufficient reasoning to ensure the best chance of it being complied with by a clinician;

- that while witnesses are not required to make a PAD valid, it is strongly encouraged that PADs are witnessed by a clinician or lawyer (or if not, by whānau) to provide evidence to an acting clinician that the PAD was made with the requisite capacity;

- update and promote pre-existing PAD templates.

Website information should be made available in audio or presentation video form. ${ }^{260}$ This is able to engage with all sectors of society who have mental illnesses, even those with reading and language disabilities.

\section{Support for advocates, NGOs, and peer support groups}

A key finding established from Part VI is that consumer advocates, NGO service providers, and peer support work are usually the first points of PAD introduction for service users. The Health and Disability Commissioner should encourage and provide resource assistance to advocates, community organisations, and peer support to launch a targeted national education programme about PADs for service users. These community organisations are able to develop a better relationship with service users, who are more likely to be in a place to plan for future crises. Again, this seeks to empower the individual and their whānau to understand a PAD for themselves.

\footnotetext{
${ }^{260}$ As they do on the National Resources Center on Psychiatric Advance Directives Website "Getting Started" (2013) NRC PAD < www.nrc-pad.org/>.
} 
C Access

\section{Lodging PADs in the EHR}

A truly effective system will have the infrastructure for clinicians to quickly access a PAD (if any exists) every time a patient is admitted for emergency care. Service users should be able to approach a DHB clinician (or their GP to lodge with the DHB) to have their PAD filed in their EHR records. Simultaneously a yellow flag should be outlined at the top of the patient's medical records to bring the clinician's attention to the $\mathrm{AD}$ within the records.

\section{National database}

In the long-term, it is recommended that the Ministry of Health create a nation-wide register for ADs of all kinds. This would be particularly helpful in situations where a patient is brought to a hospital that is unfamiliar with the patient's medical history, and is unable to verify whether the patient has a PAD based on their NHI file. This would also allow the Ministry of Health to monitor the use and enforcement of PADs, and the potential benefits, over time.

\section{Conclusion}

When utilised to their full potential, PADs are a sophisticated platform that ensures the patient's autonomous voice is considered at a time when they are most vulnerable. Overall, New Zealand service providers and patients are positive about using PADs and willing to better understand them. However practical mechanisms needed to support PAD enforcement is lacking. PADs are not well-promoted to patients that would benefit from them, clinicians do not routinely inquire into whether a patient has a PAD, and access to PADs in crisis time is inefficient. No jurisdiction to date has fully recognised the power of peer support groups and advocates in promoting and educating service users to make PADs.

Accordingly, PAD literacy of service users and their families must be improved. This improvement should be championed by advocates, NGOs and community support groups. To match this, the literacy of clinicians in enforcing PADs must also increase. The impetus to achieve this may emanate 'top-down' from legislative change. However, this must be supplemented by a 'bottom-up' education programme from guidelines which fill the gaps and aims to create a receptive service culture. 
Ultimately, any recommendations for legal and policy change will have limited impact if stakeholders do not appreciate the collaborative value of PADs; if clinicians do not respect and understand the potential for them to facilitate good practice, and patients have no confidence in PAD enforcement. This paper hopes to reinvigorate the discourse promoting PADs that was initiated by the Mental Health Commission in the early 2000s. In a system promotes the axiom "nothing about us without us", PADs are the vehicle to maximising patient involvement in mental health treatment. 


\section{Bibliography}

A Cases

$1 \quad$ New Zealand

Re $S$ [1992] 1 NZLR 363.

\section{England}

Re C (Adult: Refusal of Treatment) [1994] 1 WLR 290 [1994] 1 All ER 819 (Fam D).

Re T (Adult: Refusal of Treatment) [1993] Fam 95; [1992] 4 All ER 649 (CA).

\section{United States}

Hargrave v Vermont 340 F 3d 27 (2d Cir 2003).

In re Virgil D 524 NW 2d 894 (Wis, 1994).

Steinkruger v Miller 612 NW 2d 591 (Sd, 2000).

\section{AA Submissions in Cases}

18 Former State Mental Health Commissioners, the National Mental Health Association, and Others "Brief of 18 Former State Mental Health Commissioners, The National Mental Health Association, and others as Amici Curiae in support of the Appellees", Submission in Hargrave v Vermont 02-7160, 3 July 2002.

\section{B Legislation}

$1 \quad$ New Zealand

Bill of Rights Act 1990 (NZ).

Disability (United Nations Convention on the Rights of Persons with Disabilities) Act 2008.

Health and Disability Commissioner Act 1994.

Health and Disability Commissioner (Code of Health and Disability Services Consumers' Rights) Regulations 1996 [Code of Rights].

Mental Health (Compulsory Assessment and Treatment) Act 1992.

Protection of Personal and Property Rights Act 1988.

Wills Act 2007. 


\section{Australia}

Medical Treatment (Health Directive) Act 2006 (ACT).

3 Scotland

Adults with Incapacity (Scotland) Act 2000.

Mental Health (Care and Treatment) (Scotland) Act 2003.

4 United States

Patient Self-Determination Act of 1991 Pub L No 101-508.

\section{Treaties and Conventions}

United National Convention on the Rights of Persons with Disabilities 2515 UNTS 3 (opened for signature 30 March 2007, entered into force 3 May 2008) [UN Convention Rights].

United Nations Principles for the Protection of Persons with Mental Illness and the Improvement of Mental Health Care GA Res 46/119, A/Res/46/119 (1991).

\section{Books and Chapters in Books}

Jacqueline M Atkinson Advance Directives in Mental Health (Jessica Kingsley Publishers, London, 2007).

Phil Barker (ed) Mental Health Ethics: the Human Context (Routledge, New York, 2011).

Joanne Baxter and Rees Tapsell "Recognising and Managing mental health disorders in Maori" (2010) Best Practice Journal New Zealand 28 at 14.

Sylvia Bell and Warren Brookbanks Mental Health Law in New Zealand $\left(2^{\text {nd }}\right.$ ed, Brookers Ltd, Wellington, 2005).

A Bray and J Dawson Who benefits from welfare guardianship? A study of New Zealand law and people with intellectual disabilities (Donald Beasley Institute, Dunedin, 2000).

A Buchanan and D Brock Deciding for Others: The Ethics of Surrogate Decision Making (Cambridge University Press, London 1990).

Kate Diesfield and Ian Freckleton (eds) Involuntary Detention and Therapeutic Jurisprudence: International Perspectives on Civil Commitment (Ashgate, Aldershot, 2003).

Mason Durie Maori Health Development (Oxford University Press, Auckland, 1994).

Jonathan Herring Medical Law and Ethics $\left(2^{\text {nd }}\right.$ ed, Oxford University Press, New York, 2008). 
S Johnson (ed) Health Care and the Law ( $3^{\text {rd }}$ ed, Brookers Ltd, Wellington, 2004).

Skegg and Paterson (eds) Medical Law in New Zealand (Thomson Brookers, Wellington, 2006).

Penelope Weller New Law and Ethics in Mental Health Advance Directives: the Convention on the Rights of Persons with Disabilities and the Right to Choose (Routledge, New York, 2013)

Elizabeth Wicks Human Rights and Healthcare (Hart Publishing, Portland, 2007).

\section{E Journal Articles}

D L Ambrosini and A G Crocker "Psychiatric advance directives and the right to refuse treatment in Canada" (2007) 52 Canadian Journal of Psychiatry 397.

P Appelbaum "Psychiatric Advance Directives and Treatment of Committed Patients" (2004) 55 Psychiatric Services 751.

Jacqueline Atkinson "Ulysses' crew or Circe? - the implication of advance directives in mental health of psychiatrists" (2004) 28 Psychiatric Bulletin 3.

Atkinson and others "The development of potential models of advance directives in mental health care" (2003) 12(6) Journal of Mental Health 575.

P Backlar "Anticipatory planning for end-of-life care is not quite like anticipatory planning for psychiatric treatment” (1997) 33 Community Mental Health Journal 261.

P Backlar and BH McFarland "A survey on use of advance directives for mental health treatment in Oregon" (1996) 47 Psychiatric Services 1378.

P Backlar and others "Consumer, Provider, and Informal Caregiver Opinions on Psychiatric Advance Directives (2001) 28 Administration and Policy in Mental Health 609.

Joanne Baxter and Rees Tapsell "Recognising and Managing mental health disorders in Maori” (2010) Best Practice Journal New Zealand 28.

Jessica Berg and others "Constructing Competence: Formulating Standards of Legal Competence to Make Medical Decisions (1996) 48 Rutgers L Rev 345.

Robert Bernstein "Commentary: The Climate for Physician Adherence to Psychiatric Advance Directives" (2006) 34(3) The Journal of American Academy of Psychiatry and the Law 402.

Dan Bilsker, Elliot M Goldner and Wayne Jones "Health Service Patterns Indicate Potential Benefit of Supported Self-Management of Depression in Primary Care" (2007) 52(2)

Canadian Journal of Psychiatry 86. 
Tony Bogdanoski "Psychiatric advance directives: the new frontier in mental health law reform in Australia?" (2009) 16 JLM 891.

Dan Brock “Trumping Advance Directives” (1991) 21(5) The Hastings Center Report S5.

Danis and others "A prospective study of advance directives for life-sustaining care" (1991) 324 New England Journal of Medicine 882.

Dawson and others "Legal pitfalls of psychiatric research" (2001) 176 British Journal of Psychiatry 67.

M S DeWolf Bosek, M E Ring and R Cady, "Do Psychiatric Advance Directives Protect Autonomy?" (2008) 10(1) JONA's Healthcare Law, Ethics and Regulation 17.

R Dresser "Advance Directives: Implications for Policy" (2004) 24 Hastings Centre Report $\mathrm{S} 2$.

J Dunlap “Psychiatric Advance Directives: Having One's Say?” (2001) 89 Kentucky Law Journal 327.

Elbogen and others "Clinical decision-making and views about psychiatric advance directives" 57 Psychiatric Services 350.

R Fleischner "Advance Directives for mental health care: an analysis of State Statutes" (1998) 4 Psychology, Public Policy and Law 788.

E Gallagher "Advance directives for psychiatric care: a theoretical and practical overview for legal professionals" (1998) 4 Psychology, Public Policy and Law 746.

C Gendreau "The Rights of Psychiatric Patients in the Light of the Principles Announced by the United Nations: A recognition of the Right to Consent to Treatment?" (1997) 20(2)

International Journal of Law and Psychiatry 259.

Halpern and Szmukler "Psychiatric advance directives: Recognising autonomy and nonconsensual treatment" (1997) 21 Psychiatric Bulletin 8.

Paul Hobbs "The Limitations of Advance Directives and Statements in Mental Health" (2007) 15(1) Australian Psychiatry 22.

D E Hoffman, S I Zimmerman and C J Tompkins "The dangers of directives or the false security of forms" (1996) 24 Journal of Law and Medical Ethics 5.

Sorem Holm "Autonomy, Authenticity, or Best Interest: Everyday Decision-Making and Persons with Dementia" (2003) 4(2) Medicine, Health Care and Philosophy 153.

M Lanvin "Ulysses Contracts” (1986) 3(1) Journal of Applied Philosophy 89.

Monahan and others "Mandated Community Treatment" (2001) 52 Psychiatric Services 1192. 
D Okai and others "Mental Capacity in Psychiatric Patients: Systemic Review?" (2007) 191 The British Journal of Psychiatry 291.

RL O'Reilly "The Capacity to Execute an Advance Directive for Psychiatric Treatment" (2008) 31(1) Int'1 JL \& Psychiatry 66.

Papageorgiou and others "Advance directives for patients compulsorily admitted to hospital with serious mental illness" (2002) 181 British Journal of Psychiatry 513.

Papageorgiou and others "Advance directives for patients compulsorily admitted to hospital with serious mental disorders: Directive content and feedback from patients and professionals" (2004) 13(4) Journal of Metal Health 379.

Ross Phillips "Consumer Participation in Mental Health Research" (2006) 27 Social Policy Journal of New Zealand 171.

J Reilly and J Atkinson "The content of mental health directives: Advance statements in Scotland" (2010) 33 International Journal of Law and Psychiatry 116.

A B Rich "Medical Paternalism v Respect for Patient Autonomy: The More Things Change the More They Remain the Same" (2006) 10 Michigan State University College of Law Journal of Medicine and Law 87.

J Ritchie, R Sklar, and W Steiner "Advance directives in psychiatry" (1998) 21 International Journal of Law and Psychiatry 245.

Rosenson and Kasten "Another view of autonomy: arranging for consent in advance" (1991) 17 Schizophrenia Bulletin 1.

G Sales "The health care proxy for mental illness: can it work and should we want it?" (1993) 21 Bulletin of the American Academy of Psychiatry and the Law 161.

P S Sherman "Computer-assisted creation of psychiatric advance directives" (1998) 34 Community Mental Health Journal 351.

Srebnik and Brodoff "Implementing Psychiatric Advance Directives: Service Provider Issues and Answers" (2003) 30(3) Journal of Behavioural Health Services and Research 253.

Srebnik and others "The content and clinical utility of psychiatric advance directives" (2005) 56 Psychiatric services 592.

Srebnik and Kim "Competency for Creation, Use, and Revocation of Psychiatric Advance Directives” (2006) 34 J Am Acad Psychiatry Law 501.

P Stavis "The Nexum: a modest proposal for self-guardianship by contract. A system of advance directives and surrogate committees-at-large for the intermittently mentally ill" (1999) 16(1) Contemporary Health Law \& Policy 95. 
J Swanson and others "Psychiatric Advance Directives Among Public Mental health Consumers in Five US Cities: Prevalence, Demand and Correlates" (2006) 31 Journal of the American Academy of Psychiatry and the Law 43.

J Swanson and others "Superseding Psychiatric Advance Directives: Ethical and Legal Considerations" (2006) 34(3) Journal of the American Academy of Psychiatry and the Law 385.

Swanson and others "Psychiatric advance directives: an alternative to coercive treatment? (2000) 63 Psychiatry 160.

Van Dorn and others "Psychiatric Advance Directive and Social Workers: An Integrative Review” (2010) 55(2) Soc Work 157.

I Varekamp "Ulysses directives in the Netherlands: opinions of psychiatrists and clients" 70(1) Health Policy 291.

Pauline Wareham, Antoinette McCallin and Kate Diesfeld "Advance Directives: The New Zealand Context" (2005) 12(4) Nursing Ethics 349.

P Weller "Psychiatric Advance Directives and Human Rights" 17(2) Journal of Psychology and Law 218.

Widdershoven and Berghmans "Advance directives in psychiatric care: a narrative approach" (2001) 27(2) Journal of Medical Ethics 92.

B Winick “Advance Directive Instruments For Those with Mental Illness” (1996) 51 U Miami L Rev 57.

B Winick "The Right to Refuse Mental Health Treatment: A Therapeutic Jurisprudence Analysis” (1994) 17 Int'1 JL \& Psychiatry 99.

B Winick "Planning for the future through advance directive instruments" (1998) 4 Psychology, Public Policy and Law 579.

\section{F Official Sources}

\section{$1 \quad$ New Zealand}

Ministry of Health Mental Health and Addiction: Service Use 2009/10 (February 2013).

Wayne Naylor Sharing Patient Health Information: A review of health information privacy and electronic health records in New Zealand (Palliative Care Council of New Zealand, May 2010).

Karen O Poutasi Guidelines for Medical Practitioners Using Sections 110 and 110A of the Mental Health (Compulsory Assessment and Treatment) Act 1992 (Ministry of Health, Guidance Paper, April 2000). 
M Oakley Brown, J E Wells and K M Scott (eds) Te Rau Hinengaro: The New Zealand Mental Health Survey (Ministry of Health, September 2006).

$\mathrm{R}$ Stent A Review of the Health and Disability Commissioner Act 1994 and Code of Rights for Consumers of Health and Disability Services: Review Document for Consultation. (Health and Disability Commissioner, Consultation Document, 1999).

\section{Australia}

Australian Capital Territory Department of Health Review of the ACT Mental Health (Treatment and Care) Act 1994 (Department of Health, Options Paper, November 2007).

Human Rights Commission Resolving discrimination and harassment: a guide to making and responding to a complaint under the Human Rights Act 1993 (Human Rights Commission, Guidance Paper, October 2010).

National Advance Care Directives Working Group A National Framework for Advance Care Directives (Australian Health Ministers' Advisory Council, Consultation Document, 2011).

\section{Scotland}

Rt Hon Bruce Millan New Directions: Report on the Review of the Mental Health (Scotland) Act 1984 (SE/ 2001/ 56) [The Millan Report].

Scottish Executive Mental Health (Care and Treatment) (Scotland) Act 2003 Code of Practice (Vol 1) (August 2005).

Scottish Executive The New Mental Health Act. A Guide to Advance Statements (Scottish Executive, Guidance Paper, 2004).

\section{United States}

United States General Accounting Office Patient Self Determination Act: Providers Offer Information on Advance Directives, But Effectiveness Uncertain. (Reporting to the Ranking Minority Member, Subcommittee on Health, Committee on Ways and Means, House of Representatives, August 1995).

\section{G Internet Sources}

"The MHS 2013 S93: Advance Directives Feature Symposium: Consumers of Mental Health Services making Advance Statements: the challenges and opportunities" (23 August 2013) Mental Health Connect Blog of TheMHS Conference < mentalhealthconnect.com.au>.

Health and Disability Commissioner "Complaints Resolution Overview" (2013) Health and Disability Commissioner Website < www.hdc.org.nz>

Health and Disability Commissioner "Advance Directives in Mental Health Care and Treatment: Information for mental health service users" Mental Health Commission <www.hdc.org.nz>. 
Health and Disability Commissioner "Advance Directives, Living Wills and Questions of Competence: Presentation to the New Zealand Hospitals Association Conference 'Chance or Choice - Staying Motivated in Aged Care" (1997) Health and Disability Commissioner Website <www.hdc.org.nz>.

Human Rights and Equal Opportunity Commission "Discussion Paper: Living Wills" (1999) The Australian Human Rights Commission <www.humanrights.gov.au/publications/discussion-paper-living-wills>.

MacArthur Research Network "The MacArthur Treatment Competence Study" (2004)

MacArthur Research Network on Mental Health and Law

<www.macarthur.virginia.edu/treatment.html >.

Mental Health Foundation "Consumer/Tangata Whaiora Networks" (2013) Mental Health Foundation Website < www.mentalhealth.org.nz>.

National Advance Care Planning Cooperative "Advance Care Planning: to tatou reo" (2011) The National Advance Care Planning Cooperative Website <www.advancecareplanning.org.nz>.

National Resources Center on Psychiatric Advance Directives "Getting Started" (2013) NRC PAD < www.nrc-pad.org $>$.

National Resources Center on Psychiatric Advance Directives "Who We Are" (2013) NRC PAD < www.nrc-pad.org $>$.

New Zealand Medical Association “Advance Directives” (2007) New Zealand Medical Association website <www.nzma.org.nz>.

World Health Organisation "WHO Resource Book on Mental Health, Human Rights and Legislation" (2005) WHO Library Cataloguing-in-Publication Data <www.who.int/mental_health/>.

"Peer Network: A Definition" (2013) NZ Peer Support Network <peersupport.net.nz/resources/what-do-we-do>.

\section{H Other Sources}

D L Ambrosini "Psychiatric Advance Directives, Autonomy, and Choice: An Interdisciplinary Perspective from Law, Ethics, and Medicine" (Doctor of Philosophy Thesis, McGill University, 2011).

Harvard Health Publications "Making the most of psychiatric advance directives" (Mental Health Letter, 6 April 2006).

Pamela Wareham "New Zealanders making advance directives: A discourse analysis" (Masters in Health Science Thesis, Auckland University of Technology, 2005). 
P Weller "Advance directives and the translation of human rights principles in mental health law - towards a contextual analysis" (paper presented at the Quarterly Mental Health Consumer, Carer and Community Forum, ACT, May 2008). 
Appendix 1: Proposed parts to be added to the Mental Health (Compulsory Assessment and Treatment) Act 1992

\section{Section 2: Interpretation}

Advance Directive means a written or oral directive -

(a) by which a person makes a choice about a possible future health care procedure; and

(b) that is intended to be effective only when he or she is not competent.

\section{Section 70A: Right to have an Advance Directive considered}

(1) Every person, upon becoming a patient, who has made an Advance Directive shall have their wishes specified in that Advance Directive considered by any person giving medical treatment authorised by virtue of this Act.

(2) The responsible clinician giving medical treatment authorised by virtue of this Act shall take reasonable steps to locate the Advance Directive.

(3) The responsible clinician who makes the final decision to follow or not follow an Advance Directive shall -

(a) record in writing the circumstances in which the decision was authorised, given or made or, as the case may be, not authorised, given or made, and the reasons why; and (b) supply

(i) the person who made the Advance Directive; and

(ii) the name of the responsible clinician; and

(iii) the name of any other clinician who gave a second opinion where applicable;

with a copy of that record; and

(c) place a copy of that record with that person's medical records. 


\section{Appendix 2: HDC Pamphlet Short Exemplar}

Example of an advance directive refusing drug $\mathrm{X}^{261}$

I

do not wish to receive drug $\mathrm{X}$ under any circumstances. I have discussed this decision with my psychiatrist, Dr who has explained my treatment options and the expected benefits, risks and side effects of drug X. I confirm that I have made this decisions of my own free will and that, unless revoked by me, this is to apply for the next years.

Date

Signature

I confirm that is competent at the time of making this advance directive.

Date

Clinician

${ }^{261}$ Health and Disability Commissioner "Advance Directives in Mental Health Care and Treatment: Information for mental health service users" Mental Health Commission < www.hdc.org.nz >. 
Appendix 3: New Zealand Medical Association General AD Form

\section{ADVANCE DIRECTIVE ${ }^{262}$}

I.

of.

advise that in any circumstance that I am not competent to make a choice about a future healthcare procedure, should the following situation arise:

that I accept/decline/withdraw (delete those

which are not applicable) the following treatment/s

I confirm that information about the risks, consequences and treatment options of my decision were given (summarise below):

Name of usual doctor (or Medical Practitioner with the closest relationship with the patient)

Signed (Patient)

Signed (Doctor)

Witnessed (Contact Person)

Date

Updated/reconsidered/endorsed on

Updated/reconsidered/endorsed on

\footnotetext{
${ }^{262}$ New Zealand Medical Association “Advance Directives” (2007) New Zealand Medical Association website <www.nzma.org.nz/>.
} 


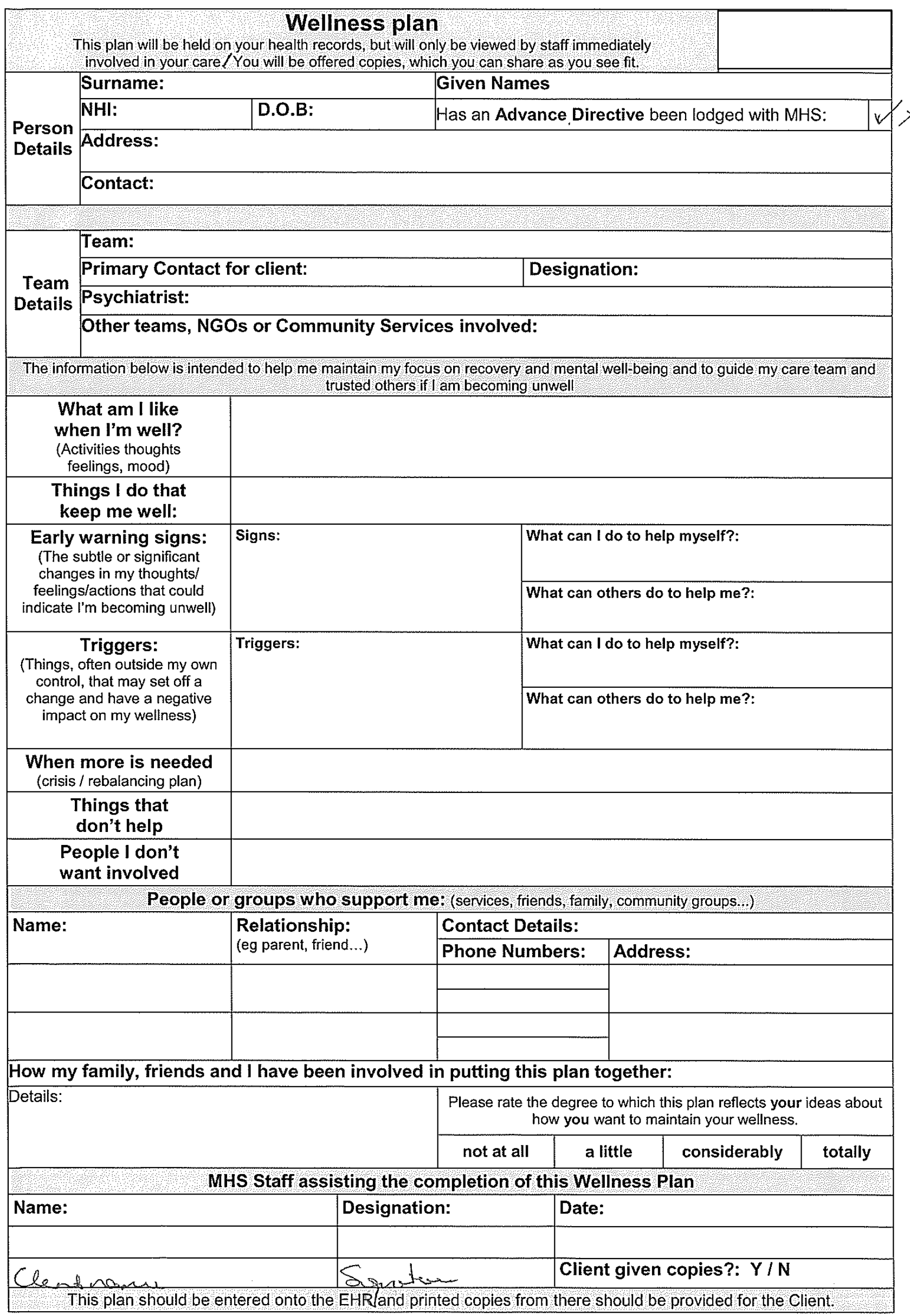


Appendix 6: Ethics approval form

TE WHARE WĀNANGA O TE ŪPOKO O TE IKA A MĀUI

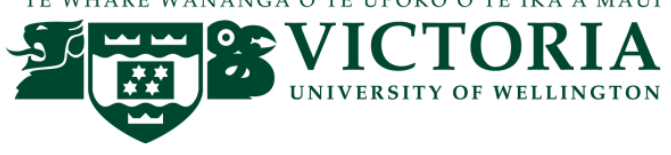

\section{HUMAN ETHICS COMMITTEE}

\section{Application for Approval of Research Projects}

Please write legibly or type if possible. Applications must be signed by supervisor (for student projects) and Head of School

Note: The Human Ethics Committee attempts to have all applications approved within three weeks but a longer period may be necessary if applications require substantial revision.

\section{NATURE OF PROPOSED RESEARCH:}

(a) Staff Research/Student Research (delete one)

(b) If Student Research ........... Degree .......LLB (Hons)... Course Code: LAWS513

(c) Project Title: Psychiatric Advance Directives

\section{INVESTIGATORS:}

(a) Principal Investigator

Name ..........Grace Liang.

Email address ..........lianggrac@myvuw.ac.nz......

School/Dept/Group .......Faculty of Law.

(b) Other Researchers N Name Position

(c) Supervisor (in the case of student research projects)

Prof Bill Atkin.

\section{DURATION OF RESEARCH}

(a) Proposed starting date for data collection ......after date of approval.....

(Note: that NO part of the research requiring ethical approval may commence prior to approval being given)

(b) Proposed date of completion of project as a whole .1 October 2013 


\section{PROPOSED SOURCE/S OF FUNDING AND OTHER ETHICAL CONSIDERATIONS}

(a) Sources of funding for the project

Please indicate any ethical issues or conflicts of interest that may arise because of sources of funding e.g. restrictions on publication of results

No external funding required

(b) Is any professional code of ethics to be followed

$\mathrm{N}$

If yes, name

(c) Is ethical approval required from any other body

$\mathrm{N}$

If yes, name and indicate when/if approval will be given

\section{DETAILS OF PROJECT}

Briefly Outline:

(a) The objectives of the project

I have chosen to focus my research on Psychiatric Advance Directives (PADs), with the objective of better understanding the extent that PADs are used in New Zealand, and ascertaining the benefits and costs of strengthening the legal framework around PADs. I hope to develop a "good practice" guide which will facilitate the use of PADs in New Zealand.

These interviews will help me better understand the role of psychiatrists/ mental health workers in mental health organisations, whether and how PADs feature - or could feature - in their work.

(b) Method of data collection

Mixture of face-to-face interviews and phone interviews. These interviews will be audio recorded with the interviewee's consent to capture missing details from notes taken during the interview.

(c) The benefits and scientific value of the project

While there has been legal literature on advance directives, there remains very little written on advance directives in the psychiatric field, and even less from a New Zealand perspective. Directives are becoming increasingly important in psychiatry, but there is insufficient publically available information for patients and loose guidelines for mental health workers. One of the objectives of this paper is to develop a good practice guideline, with recommendations for potential law reform.

(d) Characteristics of the participants

Between 6-8 medical professionals will be interviewed - e.g. psychiatrists, mental health workers. I will try to select interviewees from a range of different ethnicities, and from different types of clinics 
within the Wellington region (for instance, community mental health clinics, co-morbid mental health rehabilitation, Crisis Assessment Treatment Team)

(e) Method of recruitment

Using existing contacts and general requests through email.

(f) Payments that are to be made/expenses to be reimbursed to participants Not applicable

(g) Other assistance (e.g. meals, transport) that is to be given to participants Not applicable

(h) Any special hazards and/or inconvenience (including deception) that participants will encounter

There is a risk that an interviewee may mention or identify a patient. It will be made clear to the interviewee prior to the interview that I am not asking for any such (identifying) information. If a participant does mention a patient, this will not be recorded in the interviewer's notes.

(i) State whether consent is for (delete where not applicable):

(i) the collection of data

(ii) attribution of opinions or information

(iii) release of data to others

(iv) use for a conference report or a publication

(iv) use for some particular purpose (specify)

Research paper

Attach a copy of any questionnaire or interview schedule to the application

(j) How is informed consent to be obtained (see sections 4.1, 4.5(d) and 4.8(g) of the Human Ethics Policy)

(i) the research is strictly anonymous, an information sheet is $\mathrm{N}$ supplied and informed consent is implied by voluntary participation in filling out a questionnaire for example (include a copy of the information sheet)

(ii) the research is not anonymous but is confidential and informed consent will be obtained through a signed consent form (include a copy of the consent form and information sheet)

(iii) the research is neither anonymous or confidential and informed consent will be obtained through a signed consent form (include a copy of the consent form and information sheet)

(iv) informed consent will be obtained by some other method $\mathrm{N}$ (please specify and provide details) 
With the exception of anonymous research as in (i), if it is proposed that written consent will not be obtained, please explain why

(k) If the research will not be conducted on a strictly anonymous basis state how issues of confidentiality of participants are to be ensured if this is intended. (See section 4..1(e) of the Human Ethics Policy). (E.g. who will listen to tapes, see questionnaires or have access to data). Please ensure that you distinguish clearly between anonymity and confidentiality. Indicate which of these are applicable.

(i) access to the research data will be restricted to the investigator $\mathrm{N}$

See (ii) below - Supervisor will also have access to the research

data.

(ii) access to the research data will be restricted to the investigator $\mathrm{Y}$ and their supervisor (student research)

(iii) all opinions and data will be reported in aggregated form in $\mathrm{N}$ such a way that individual persons or organisations are not identifiable

(iv) Other (please specify)

Publication of information will not single-out any individual. If individuals are quoted, no names will ever be used (Instead, it will be worded for example 'one [person] stated...")

(l) Procedure for the storage of, access to and disposal of data, both during and at the conclusion of the research. (see section 4.12 of the Human Ethics Policy). Indicate which are applicable:

(i) all written material (questionnaires, interview notes, etc) will be $\mathrm{Y}$ kept in a locked file and access is restricted to the investigator

(ii) all electronic information will be kept in a password-protected $\mathrm{Y}$ file and access will be restricted to the investigator

(iii) all questionnaires, interview notes and similar materials will be destroyed:

(a) at the conclusion of the research

(b)......2.......years after the conclusion of the research; or

(iv) any audio or video recordings will be returned to participants $\mathrm{Y}$ and/or electronically wiped

(v) other procedures (please specify): 
If data and material are not to be destroyed please indicate why and the procedures envisaged for ongoing storage and security

(m) Feedback procedures (See section 7 of Appendix 1 of the Human Ethics Policy). You should indicate whether feedback will be provided to participants and in what form. If feedback will not be given, indicate the reasons why.

Participants can indicate on the participant consent form if they wish to receive a copy of the finished research paper. This will be emailed to them after the conclusion of the research.

(n) Reporting and publication of results. Please indicate which of the following are appropriate. The proposed form of publications should be indicated on the information sheet and/or consent form.

(i) publication in academic or professional journals $\quad \mathrm{Y}$

(ii) dissemination at academic or professional conferences $\quad \mathrm{Y}$

(iii) deposit of the research paper or thesis in the University Library $\mathrm{Y}$ (student research)

(iv) other (please specify)

$\mathrm{N}$

Signature of investigators as listed on page 1 (including supervisors) and Head of School.

NB: All investigators and the Head of School must sign before an application is submitted for approval

Date.

Date

Date

Head of School:

Date. 


\section{TE WHARE WĀNANGA O TE ŪPOKO O TE IKA A MĀUI 5y UNIVERSITY OF WELLINGTON \\ Information sheet for Participants \\ Research on Psychiatric Advance Directives for LAWS513 Law and Medicine Research Paper}

\section{1) Introduction}

My name is Grace Liang, and I am a final year Bachelor of Law (Hons) student at Victoria University of Wellington. I am currently writing my 15,000 word research paper for LAWS513, a special topic paper on Law and Medicine taken as part of the Honours programme.

I have chosen to focus my research on Psychiatric Advance Directives (PADs), with the objective of better understanding the extent that PADs are used in New Zealand, and ascertaining the benefits and costs of strengthening the legal framework around PADs. I hope to develop a "good practice" guide which will facilitate the use of PADs in New Zealand.

These interviews will help me better understand the role of psychiatrists/ mental health workers in mental health organisations, whether and how PADs feature - or could feature - in their work.

As well as providing an indication of what mental health workers already know about PADs, the questions I would like to ask you pose hypothetical scenarios to understand whether you think PADs will provide any benefits to patients as well as mental health workers, and in what circumstances you would use them.

Victoria University of Wellington's Human Ethics Committee has approved this research. If you choose to participate after reading this information sheet and clarifying any questions, you will be asked to sign a consent form.

\section{2) Methodology}

I will interview a small number of experienced mental health workers from various organisations within the Wellington region. There will be a mixture of face-to-face 
interviews and phone interviews. All interviews will be audio-recorded, and written notes taken during the interview. Interviews will not take longer than 60 minutes.

\section{3) Role of the participant}

Personal details of participants and information provided by participants will be treated as confidential. Note that I am not requesting any information about any patients you may have dealt with. Publication of information will not single-out any individual. If individuals are quoted, no names will ever be used (Instead, it will be worded for example 'one [person] stated...")

\section{4) Rights of the participant}

Participants will have the right to check the interview notes, and specify that certain comments not be used for research purposes. Participants have the right to withdraw from the research within two week after receiving the notes to check, after which I will assume that person will not withdraw. If a participant chooses to withdraw, all data collected will be destroyed.

Please indicate on the participant consent form if you wish to receive a copy of the finished research paper. This will be emailed to you after the conclusion of the research.

\section{5) Treatment of data}

Access to research data will be restricted to me (the student researcher) and my supervisor, Bill Atkin. All information collected will be treated as confidential, and will be protected by secure storage methods. Raw information collected including audio recordings will be kept for two years, from which time it will be destroyed.

\section{6) Publication of data}

Information collected from interviews will be analysed for the 15,000 word research paper. A chart collating the responses to the questions may be included in an appendix to the paper, but this data will be presented in a way that will not identify the individual participants.

This paper is to be handed in to the Faculty of Law on the 1 October 2013, and a copy of the research paper will be held permanently in the Victoria University Library (for student research purposes). An edited version may be published in academic or professional journals or be used at a conference.

\section{7) Contact Details}

\section{Student Researcher}

Grace Liang

lianggrac@myvuw.ac.nz 
Cell: 0273401103

Landline: (04) 8017598

Supervisor

Prof Bill Atkin

Bill.atkin@vuw.ac.nz 


\section{PARTICIPANT CONSENT FORM}

Interview on Psychiatric Advance Directives for LAWS513 Law and Medicine

Research Paper by Grace Liang

$\mathrm{I}$, , in participating in this research project

- have been provided with adequate information relating to the nature and objectives of this research project, I have understood the information provided to me and have been given the opportunity to seek further clarification;

- understand that I may withdraw from this research within two week after receiving interview notes to check;

- understand that if I withdraw from the project, any data I have provided will be destroyed;

- understand that information or opinions I provide will be kept confidential and reported in a way that will not identify any individual person;

- understand that should a patient be identified in the interview process, the name will not be recorded in any interview notes or transcripts;

- understand that the information I have provided will be used only for this research project and that any further use will require my written consent;

- understand that when this research is completed the information obtained will be destroyed after two years.

$\square$ I would like a copy of the research paper emailed to me Email address

Signature 


\section{Interview Questions \\ Research on Psychiatric Advance Directives for LAWS513 Law and Medicine Research Paper}

\section{Interview Questions}

1. Explain what your day-to-day role is at [organisation $\mathrm{X}$ ].

2. What type of patients do you work with? (If possible, specify the type of mental illnesses you deal with most).

3. Describe what you know about Psychiatric Advance Directives (PADs)

4. Where did you learn about PADs?

5. Have you had any formal education in PADs (formal meaning any tertiary education or training)

6. What do you think is the general attitude of clinicians AND patients to the idea of making and implementing PADs?

7. Have you ever recommended that a patient make a PAD?

8. Have any of your previous patients ever requested a PAD?

9. Have you ever helped a patient complete a PAD?

10. If no Q9, why have you not recommended a PAD previously?

11. Have you ever had to apply a PAD in a crisis scenario (treat someone using a PAD)?

12. If yes to Q10, did you follow the PAD? To what extent did you follow the PAD?

13. In your experience, what type of PADs have you encountered? Try and describe the content and form without identifying the patient.

\section{Start here if answered "no" to Q8 [or continue on from Q13]}

14. Would you ever recommend that a patient make a PAD?

15. If yes, what type of patients would you recommend make a PAD? In what circumstances would it be appropriate for clinicians to recommend PADs?

16. Should different types of PADs apply to different patients? (e.g. PADs for specific treatment vs more vaguely worded PADs). 
17. If you were to recommend that a patient make a PAD, can you describe the process you would go through with the patient? What sorts of things do you think could be included in a PAD? What sorts of things should be excluded?

18. Does the organisation/ clinic that you work for have a PAD regime? (e.g. a form to fill, information pamphlet, anything quasi-PAD?)

19. What do you understand about the legal standing of PADs in New Zealand? (what legal force do PADs have in NZ?)

20. In your work, what are the benefits of having and promoting the use of PADs?
a. For clinicians?
b. For nurses?
c. For patients themselves?

21. Do you personally have any reservations about the process:
a. Making a PADs? [capacity; form etc]
b. Changing/altering/monitoring PADs?
c. Enforcing PADs?

Why do you hold these reservations?

22. In your work, what would be costs/ obstacles/ barriers of having/ implementing PADs?
a. For clinicians?
b. For nurses?
c. For patients themselves?

23. Based on your answer to Q20 and 21, do you think more patients should make PADs where appropriate?

24. Do you think legally binding PAD orders would be workable?

a. In what circumstances?

25. Do you think PADs need a stronger framework or governing standard in New Zealand? Should there be a duty on doctors to inform?

If yes, in what situations?

1. All?

2. Most serious cases?

3. People who have been subject to compulsory care previously?

26. Should there be a "good practice" guide developed for clinicians?

27. Should there be a standard "form" or should we allow individual hospitals to create their own? 